Article

\title{
Design and Modeling of Polysilicon Electrothermal Actuators for a MEMS Mirror with Low Power Consumption
}

\author{
Miguel Lara-Castro ${ }^{1}$, Adrian Herrera-Amaya ${ }^{2}$, Marco A. Escarola-Rosas ${ }^{1}$, \\ Moisés Vázquez-Toledo ${ }^{3}$, Francisco López-Huerta ${ }^{4, *}$, Luz A. Aguilera-Cortés ${ }^{2}$ and \\ Agustín L. Herrera-May ${ }^{1}$ \\ 1 Micro and Nanotechnology Research Center, Universidad Veracruzana, Calzada Ruiz Cortines 455, \\ Boca del Río, VER 94294, Mexico; septmig@gmail.com (M.L.-C.); maerescarola@gmail.com (M.A.E.-R.); \\ leherrera@uv.mx (A.L.H.-M.) \\ 2 Depto, Ingeniería Mecánica, Campus Irapuato-Salamanca, Universidad de Guanajuato/Carretera \\ Salamanca-Valle de Santiago Km. $3.5+1.8$ km, Salamanca, GTO 36885, Mexico; \\ herreraugto@gmail.com (A.H.-A.); aguilera@ugto.mx (L.A.A.-C.) \\ 3 Sistemas Automatizados, Centro de Ingeniería y Desarrollo Industrial/Av. Pie de la Cuesta No. 702, \\ Desarrollo San Pablo, Querétaro 76125 México; moises.vazquez@cidesi.edu.mx \\ 4 Engineering Faculty, Universidad Veracruzana, Calzada Ruiz Cortines 455, Boca del Río, \\ Veracruz 94294, Mexico \\ * Correspondence: frlopez@uv.mx; Tel.: +52-229-775-2000
}

Received: 14 January 2017; Accepted: 20 June 2017; Published: 25 June 2017

\begin{abstract}
Endoscopic optical-coherence tomography (OCT) systems require low cost mirrors with small footprint size, out-of-plane deflections and low bias voltage. These requirements can be achieved with electrothermal actuators based on microelectromechanical systems (MEMS). We present the design and modeling of polysilicon electrothermal actuators for a MEMS mirror $(100 \mu \mathrm{m} \times 100 \mu \mathrm{m}$ $\times 2.25 \mu \mathrm{m})$. These actuators are composed by two beam types $(2.25 \mu \mathrm{m}$ thickness $)$ with different cross-section area, which are separated by $2 \mu \mathrm{m}$ gap. The mirror and actuators are designed through the Sandia Ultra-planar Multi-level MEMS Technology V (SUMMiT V ${ }^{\circledR}$ ) process, obtaining a small footprint size $(1028 \mu \mathrm{m} \times 1028 \mu \mathrm{m})$ for actuators of $550 \mu \mathrm{m}$ length. The actuators have out-of-plane displacements caused by low dc voltages and without use material layers with distinct thermal expansion coefficients. The temperature behavior along the actuators is calculated through analytical models that include terms of heat energy generation, heat conduction and heat energy loss. The force method is used to predict the maximum out-of-plane displacements in the actuator tip as function of supplied voltage. Both analytical models, under steady-state conditions, employ the polysilicon resistivity as function of the temperature. The electrothermal-and structural behavior of the actuators is studied considering different beams dimensions (length and width) and dc bias voltages from 0.5 to $2.5 \mathrm{~V}$. For $2.5 \mathrm{~V}$, the actuator of $550 \mu \mathrm{m}$ length reaches a maximum temperature, displacement and electrical power of $115^{\circ} \mathrm{C}, 10.3 \mu \mathrm{m}$ and $6.3 \mathrm{~mW}$, respectively. The designed actuation mechanism can be useful for MEMS mirrors of different sizes with potential application in endoscopic OCT systems that require low power consumption.
\end{abstract}

Keywords: electrothermal actuators; endoscopic optical-coherence tomography; microelectromechanical systems (MEMS) mirror; polysilicon; SUMMiT V

\section{Introduction}

Microelectromechanical systems (MEMS) have allowed the develop of devices with advantages such as low cost, small size, high reliability, fast response and easy integration with electronic 
circuits [1-3]. Among these devices, MEMS mirrors have potential applications such as projection displays [4], tunable optical filter [5], tunable laser [6], Fourier transform spectrometer system [7], confocal scanning microendoscope [8], optical bio-imaging [9] and optical coherence tomography [10]. For 3D endoscopic optical-coherence tomography (OCT) systems are necessary low cost MEMS mirrors composed by compact structures that have large out-of-plane deflections, minimum bias voltage and orthogonal scanning capacity $[11,12]$. These systems are minimally invasive and can have high resolution and reliability [12]. For this, the mirrors need high precision actuators that allow the variation of their tilting angles with low power consumption [13]. To adjust and control the mirror motion can use different actuators types, including the electromagnetic [14,15], electrostatic [16], electrothermal $[17,18]$ or piezoelectric $[19,20]$ actuators.

Mirrors with electrostatic actuators have a fast speed, a small mechanical scanning range at non-resonance (generally $2^{\circ}-3^{\circ}$ ) and a large actuator footprint, which can be increased at resonance [21,22]. This actuation mechanism requires complex fabrication and high drive voltages about $100 \mathrm{~V}$ [23], which constraints its application in endoscopic OCT systems. Other actuators are the electromagnetics that generate large displacements with small driving voltage and have fast response time as well as high resonance frequency [24-26]. Although electromagnetic mirrors register problems with electromagnetic interference (EMI) and need precise assembly techniques of magnetic materials and metallic coils, limiting they use in endoscopic imaging [26]. On the other hand, piezoelectric actuators offer a large motion range combined with high speed and low electric energy [27]. Nevertheless, there are several challenges of the MEMS mirrors to develop endoscopic imaging such as charge leakage, coupling nonuniformity and hysteresis [28]. Other option is a MEMS mirror with an electrothermal actuation mechanism, which has large deflections caused by low bias voltage and does not present EMI and electrostatic discharging problems [28-32]. However, these mirrors require to decrease their footprint size, operation temperature and bias voltage as well as simplify their mechanical structure and performance. To overcome several of these challenges, we propone the design of polysilicon electrothermal actuators for MEMS mirrors based on the Sandia Ultra-planar Multi-level MEMS Technology V (SUMMiT V ${ }^{\circledR}$ ) process from Sandia National Laboratories. This electrothermal actuation mechanism has a simple structural configuration composed by an array of four polysilicon actuators, which can achieve out-of-plane displacements with low dc voltages. These actuators do not require materials with different thermal expansion coefficients due to that employ polysilicon layers with distinct wide, which are separated by $2 \mu \mathrm{m}$ gap. This device has a small footprint size $(1028 \mu \mathrm{m}$ $\times 1028 \mu \mathrm{m}$ ), compact structure and simple performance with reduced temperatures. The proposed design includes the modeling of temperature behavior and maximum displacements of the actuators under steady-state conditions. Our actuation mechanism can be used for the rotation of MEMS mirrors of different sizes. The rotation orientation of the mirror can be adjusted through the selective biasing of the four actuators. Thus, the proposed design could be considered for potential applications in endoscopic OCT systems.

This paper is organized as follows. Section 2 contains the design and modeling of the proposed actuation mechanism, which includes its electrothermal and structural behavior. Section 3 shows the results and discussions of temperature and out-of-plane displacements of the actuators using analytical models. Finally, the paper ends with the conclusion and future researches.

\section{Design and Modeling}

This section presents the design and modeling of the electrothermal actuators for a MEMS mirror. It considers the temperature distribution and out-of-plane displacements of the actuators generated by different dc biasing voltages under steady-state conditions.

\subsection{Structural Configuration}

Figure 1 shows the design of a MEMS mirror with an array of four polysilicon electrothermal actuators and springs, which are based on the SUMMiT V process [33]. The surface of the silicon 
substrate below of the actuators and mirror must be etched to allow the free motion of the actuators and mirror, as shown in Figure 2. Each actuator has two polysilicon structural layers (i.e., poly3 and poly4 of the SUMMiT V process) of $2.25 \mu \mathrm{m}$ thickness with different cross-section area, separated by $2 \mu \mathrm{m}$ gap. Thus, the electrical resistances of these layers are not equal, which allow a temperature change along the actuator when an electrical current is applied. It generates out-of-plate displacements of the actuator due to Joule effect, whose amplitudes can be controlled varying the current values. Thus, this actuator does not need materials layers with different thermal expansion coefficients that simplify its fabrication process. This design includes actuators with inverted structural layers to achieve out-of-plane motions with opposite directions, as shown in Figure 3a,b. Thereby, the mirror is connected to two pair actuators with inverted layers that can have displacements in opposite directions, increasing the tilting angle of the mirror. In addition, four polysilicon springs (508 $\mu \mathrm{m}$ length, $5 \mu \mathrm{m}$ width and $2.25 \mu \mathrm{m}$ thickness) with low stiffness are employed to connect the actuators with the mirror. Due to the small cross-section area and large length of each spring, the four springs have high electrical resistance that constraint the current flow through them. In this work, the effect of the thermal energy through the springs and mirror is not considered.

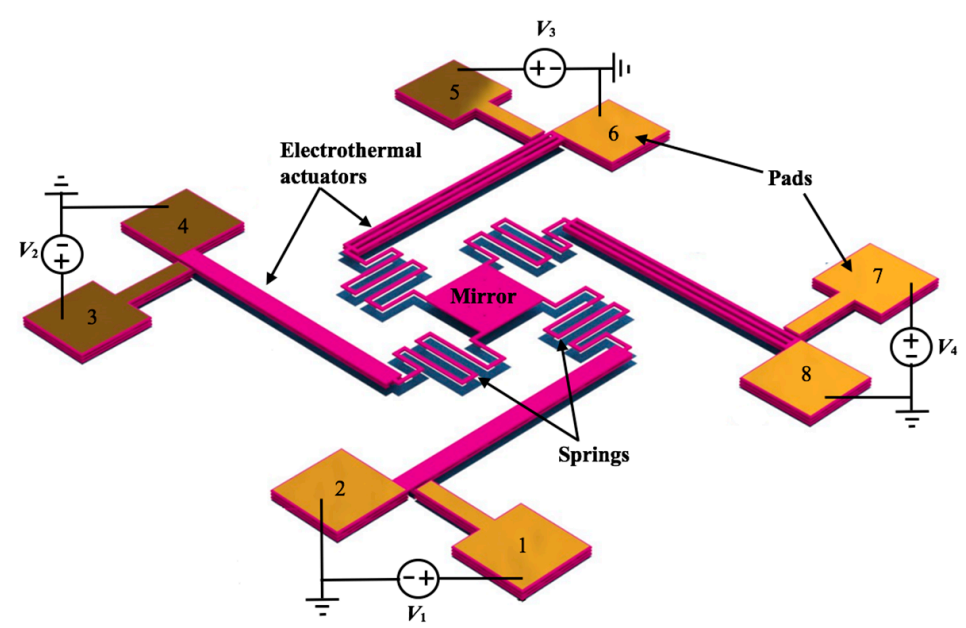

Figure 1. Design of an electrothermal actuation mechanism for the rotation of a microelectromechanical systems (MEMS) mirror.

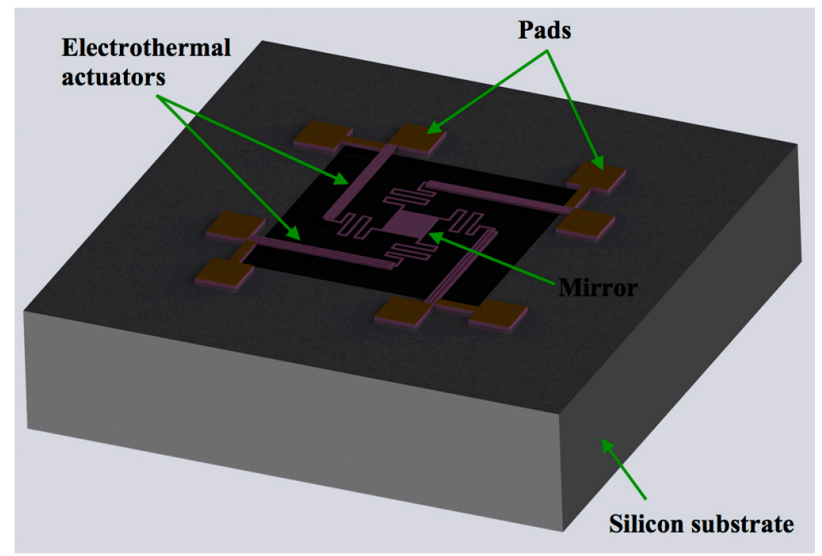

Figure 2. View of the MEMS mirror design in a silicon die.

In the design stage, the temperature and out-of-plane displacements of the actuators considering different dimensions of length $\left(L_{i}\right)$ and width $\left(\omega_{h}\right.$ and $\left.\omega_{c}\right)$ of the upper (hot) and bottom (cold) beams are studied. The first structural layer is formed by a polysilicon beam $\left(\omega_{c}\right)$ and the second layer 
is composed by three polysilicon beams of width $\omega_{h}$ each one, in which $\omega_{h}<<\omega_{c}$. Figure $3 a, b$ depicts views of the hot and cold beams in two electrothermal actuators with deflections in opposite directions. In addition, the mirror and springs are designed using the poly4 layer of SUMMiT V process. In this fabrication process, on the mirror surface can be deposited an aluminum layer $(96 \mu \mathrm{m} \times 96 \mu \mathrm{m} \times 0.7 \mu \mathrm{m})$. The springs have a connection with low stiffness between the actuators and mirror, which lets higher mirror tilting.

The operating principle of the electrothermal actuator with bending motion is caused by the asymmetrical thermal expansion of the two structural layers with different cross section area and electrical resistance. The resistance of the narrower layer is higher than that of the wider layer. If a dc bias voltage is applied at the end of the two layers (see Figure $3 a, b$ ) then a current flows through them, generating an increase of temperature in both layers. Due to the difference in the electrical resistance of the two layers, the temperature and dissipated energy in the narrower layer (high electrical resistance) is larger than the wider layer (low electrical resistance). This allows more thermal deformation of the narrower layer, which forces the actuator tip to an out-of-plane motion towards the wider layer. Therefore, the difference of the thermal deformation between the two actuator layers generates an out-of-plane motion. Figure $3 \mathrm{c}$ depicts the main geometrical parameters of an electrothermal actuator. In this work, we consider actuators with three different lengths ( $350 \mu \mathrm{m}, 450 \mu \mathrm{m}$ and $550 \mu \mathrm{m})$, constant thickness $\left(t_{h}=t_{c}=2.25 \mu \mathrm{m}\right.$ ) and variable width (i.e., $w_{h}$ of $2 \mu \mathrm{m}$ to $5 \mu \mathrm{m}$ and $w_{c}$ of $20 \mu \mathrm{m}$ to $30 \mu \mathrm{m}$ ).

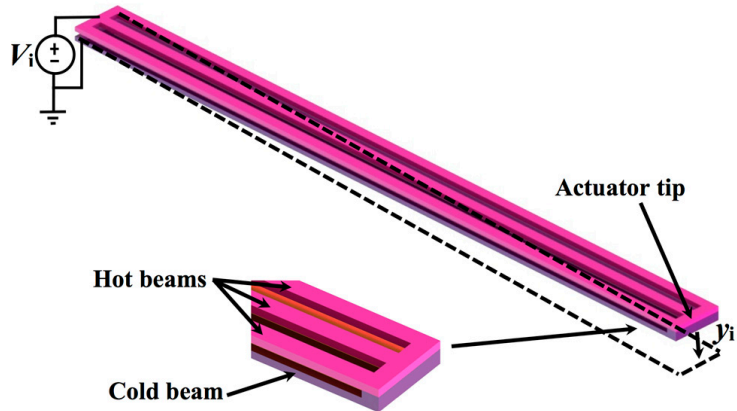

(a)

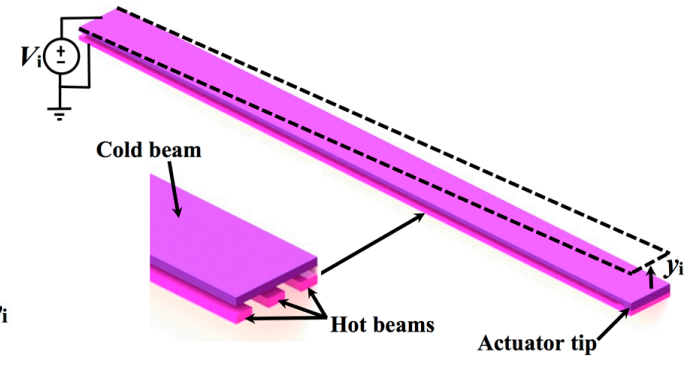

(b)

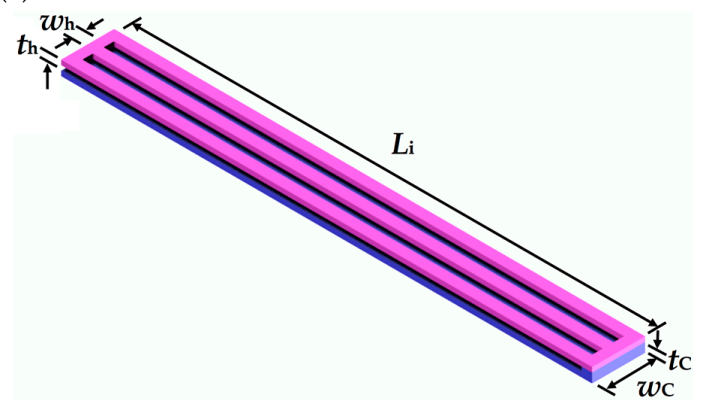

(c)

Figure 3. View of out-of-plane displacements, $y_{i}$, with directions (a) downward and (b) upward of two electrothermal actuators with inverted structural layers due to Joule effect; (c) geometrical parameters of the hot and cold beams of an electrothermal actuator.

\subsection{Electrical Model of Electrothermal Actuators}

An equivalent electric circuit of the electrothermal actuator is developed to predict the voltage drop along its hot and cold beams, as shown in Figure 4. For this case, $R_{1}, R_{2}$ and $R_{3}$ are the electrical resistance values obtained for each hot beam $\left(\omega_{h}\right)$, cold beam $\left(\omega_{c}\right)$ and connection between both beams, respectively. These resistances are calculated including the dimensions of the beams and the resistivity of the polysilicon layers. For instance, Table 1 shows the values of the electrical resistances for an electrothermal actuator with the following dimensions: $L_{h}=L_{c}=450 \mu \mathrm{m}, \omega_{h}=5 \mu \mathrm{m}, \omega_{c}=30 \mu \mathrm{m}$ and $t_{h}=t_{c}=2.25 \mu \mathrm{m}$. 


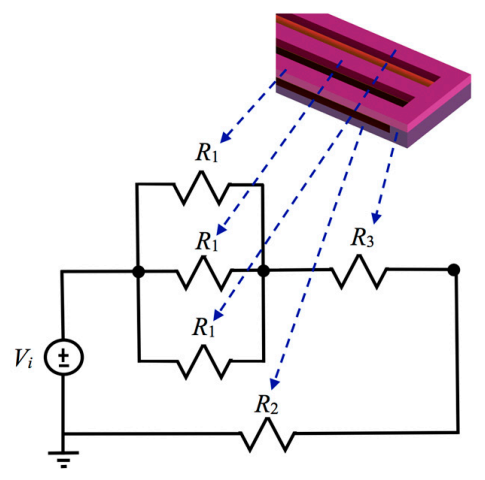

Figure 4. Schematic of equivalent electrical circuit of an electrothermal actuator.

Table 1. Resistance values of the equivalent electrical circuit of an electrothermal actuator considering the following dimensions: $\omega_{h}=2 \mu \mathrm{m}, \omega_{c}=30 \mu \mathrm{m}$ and $t_{h}=t_{c}=2.25 \mu \mathrm{m}$.

\begin{tabular}{cccc}
\hline \multirow{2}{*}{ Parameter } & \multicolumn{3}{c}{ Electrical Resistance $(\Omega)$} \\
\cline { 2 - 4 } & $\boldsymbol{L}_{\boldsymbol{h}} \mathbf{=} \mathbf{3 5 0} \boldsymbol{\mu \mathrm { m }}$ & $\boldsymbol{L}_{\boldsymbol{h}}=\mathbf{4 5 0} \boldsymbol{\mu \mathrm { m }}$ & $\boldsymbol{L}_{\boldsymbol{h}}=\mathbf{5 5 0} \boldsymbol{\mu \mathrm { m }}$ \\
\hline$R_{1}$ & 1576.6 & 2027 & 2077.4 \\
$R_{2}$ & 105.1 & 135.1 & 165.2 \\
$R_{3}$ & 1.7 & 1.7 & 1.7 \\
\hline
\end{tabular}

\subsection{Analytical Modeling of the Electrothermal and Structural Behavior}

The electrothermal behavior of a polysilicon beam with length larger than its thickness and width can be simplified using an analysis in one dimension [31]. The electrothermal actuator (see Figure 3a) can be decomposed into three line-shape beams connected in series. For this, the first line-shape beam is obtained combining the three upper beams (hot beams) in a wider beam. Thus, the first line-shape beam has an equivalent electrical resistance equal to a third of the resistance of an upper beam. The second line-shape beam is formed by the connection between the upper and bottom beams, which has a $2.5 \mu \mathrm{m}$ gap. In addition, the bottom (cold) beam forms the third line-shape beam. For this case, we assumed that the length of the upper (hot) beam $\left(L_{h}\right)$ is equal to the length of the bottom beam $\left(L_{c}\right): L_{h}=L_{c}=L$. Figure 5 shows a differential element for the thermal analysis of the actuator.

In Figure $5 b$, heat flow equation is obtained by examining a differential element of polysilicon beam of width $w$, thickness $t$ and length $\Delta$ s. Assuming steady-state conditions, resistive heating power in the differential element is equal to heat conduction out of the element. Therefore, the energy balance of the differential element of the beam with heat losses can be expressed as [31]:

$$
-k_{p} w t\left[\frac{d T}{d s}\right]_{s}+J^{2} \rho w t \Delta s-Q \Delta s w \frac{T-T_{0}}{R_{t}}=-k_{p} w t\left[\frac{d T}{d s}\right]_{s+\Delta s}
$$

where $J$ is the current density, $k_{p}$ is the thermal conductivity and $\rho$ is the resistivity of the polysilicon, $T$ is the operation temperature, $T_{0}$ is the substrate temperature, $Q$ is the shape factor that includes the impact of the element shape on heat conduction to the substrate and $R_{t}$ is the thermal resistance generated by the substrate and actuator that are considered wide enough [31]:

$$
R_{t}=\frac{t_{a}}{k_{a}}+\frac{t_{n}}{k_{n}}+\frac{t_{s}}{k_{s}}
$$

where $t_{a}$ is the distance between both the bottom beam of the actuator and $\mathrm{Si}_{3} \mathrm{~N}_{4}$ surface, $t_{n}$ is the thickness of the $\mathrm{Si}_{3} \mathrm{~N}_{4}$ film, $t_{s}$ is the thickness of the $\mathrm{SiO}_{2}$ film and $k_{a}, k_{n}$ and $k_{s}$ are the thermal conductivity of air, $\mathrm{Si}_{3} \mathrm{~N}_{4}$ and $\mathrm{SiO}_{2}$ films, respectively. 


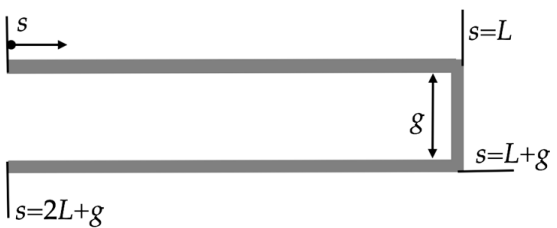

(a)

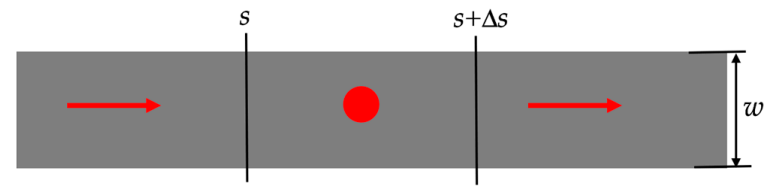

(b)

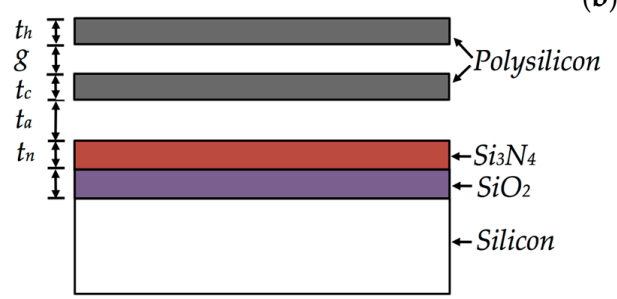

(c)

Figure 5. (a) Schematic of the one-dimensional model for an electrothermal actuator; (b) its differential element; and (c) cross-section of the different layers for the thermal analysis.

The shape factor $Q$ for the heat conduction is given by [34]:

$$
Q=\frac{t}{w}\left(\frac{2 t_{a}}{t}+1\right)+1
$$

To apply Equation (3) in the electrothermal actuator, we approximated $t=t_{h}=t_{c}$ and $w=w_{c}$. The resistivity of polysilicon, $\rho(T)$, depends of the temperature and its value is determined by:

$$
\rho(T)=\rho_{0}\left[1+\xi\left(T-T_{0}\right)\right]
$$

where $\rho_{0}$ is the initial resistivity at the substrate temperature and $\xi$ is the linear temperature coefficient.

Considering the limit as $\Delta s \rightarrow 0$ for Equation (1), the following second-order differential equation is obtained:

$$
k_{p} \frac{d^{2} T}{d s^{2}}+J^{2} \rho=\frac{Q}{t} \frac{\left(T-T_{0}\right)}{R_{t}}
$$

The first term on the left of Equation (5) indicates the net rate of heat conduction into the element per unit volume. The rate of heat energy generation inside the element per unit volume is represented by the second term on the left. Finally, the rate of heat energy loss of the element per unit volume is considered in the term of the right side. Substituting Equation (4) into Equation (5), we obtain:

$$
\frac{d^{2} T}{d s^{2}}-m^{2} T=-m^{2} T_{0}-\frac{J^{2} \rho_{0}}{k_{p}}
$$

with

$$
m^{2}=\frac{Q}{k_{p} R_{t} t}-\frac{J^{2} \rho_{0} \xi}{k_{p}}
$$

Solving Equation (6) and applying the solution to the upper (hot) and bottom (cold) beams, we get the following temperature distribution:

$$
\begin{aligned}
& T_{h}(s)=C_{1} e^{m_{h} s}+C_{2} e^{-m_{h} s}+T_{o}+\frac{J_{h}^{2} \rho_{0}}{k_{p} m_{h}^{2}} \\
& T_{c}(s)=C_{3} e^{m_{c} s}+C_{4} e^{-m_{c} s}+T_{o}+\frac{J_{c}^{2} \rho_{0}}{k_{p} m_{c}^{2}}
\end{aligned}
$$


with

$$
\begin{aligned}
& m_{h}^{2}=\frac{Q}{k_{p} R_{t} t}-\frac{J_{h}^{2} \rho_{0} \xi}{k_{p}} \\
& m_{c}^{2}=\frac{Q}{k_{p} R_{t} t}-\frac{J_{c}^{2} \rho_{0} \xi}{k_{p}}
\end{aligned}
$$

where $T_{h}(s)$ and $T_{c}(s)$ are the temperature distribution along the upper (hot) and bottom (cold) beams, respectively, and $J_{h}$ and $J_{c}$ are the current density through the upper and bottom beams, respectively.

To determine the constants $C_{i}$, we assume a temperature on the anchor pads equal to the substrate temperature (i.e., $T_{h}(0)=T_{0}$ and $\left.T_{c}(2 L+g)=T_{0}\right)$, a continuity of both temperature (i.e., $T_{h}(L)=$ $\left.T_{c}(L)\right)$ and rate of heat conduction (i.e., $\left.3 w_{h} d T_{h}(L) / d s=w_{c} d T_{c}(L) / d s\right)$ across the join point of the upper and bottom beams. By assuming these boundary conditions, the following matrix equation is determined as:

$$
\left[\begin{array}{cccc}
1 & 1 & 0 & 0 \\
e^{m_{h} L} & e^{-m_{h} L} & -e^{m_{c} L} & -e^{-m_{c} L} \\
3 \omega_{h} m_{h} e^{m_{h} L} & -3 \omega_{h} m_{h} e^{-m_{h} L} & -\omega_{c} m_{c} m_{c} L & \omega_{c} m_{c} e^{-m_{c} L} \\
0 & 0 & e^{m_{c}(2 L+g)} & e^{-m_{c}(2 L+g)}
\end{array}\right]\left[\begin{array}{c}
C_{1} \\
C_{2} \\
C_{3} \\
C_{4}
\end{array}\right]=\left[\begin{array}{c}
-\frac{J_{h}^{2} \rho_{0}}{k_{p} m_{h}^{2}} \\
\frac{J_{c}^{2} \rho_{0}}{k_{p} m_{c}^{2}}-\frac{J_{h}^{2} \rho_{0}}{k_{p} m_{h}^{2}} \\
0 \\
-\frac{J_{c}^{2} \rho_{0}}{k_{p} m_{c}^{2}}
\end{array}\right]
$$

The coefficients $C_{i}$ of Equation (12) are determined using operations on matrices. Next, these coefficients are employed into Equations (8) and (9) to calculate the temperature increase along the upper and bottom beams due to bias voltages. These coefficients are calculated as:

$$
\begin{gathered}
C_{1}=\frac{A(3+d)-e^{m_{h} L}\left[B d\left(1+e^{2 m_{c}(L+g)}\right)+2 D d e^{m_{c}(L+g)}\right]-A(3-d) e^{2 m_{c}(L+g)}}{(d-3) e^{2 m_{c}(L+g)}-(d+3) e^{2\left(m_{c}(L+g)+m_{h} L\right)}+e^{m_{h} L}(3-d)\left(e^{m_{h} L}+e^{-m_{h} L}\right)} \\
C_{2}=\frac{\left(B d+A(3-d) e^{m_{h} L}+\left(d(B+2 D)-A(3+d) e^{m_{h} L}\right) e^{2 m_{c}(L+g)}\right) e^{m_{h} L}}{\left(d-3-(d+3) e^{2 m_{h} L}\right) e^{2 m_{c}(L+g)}+2\left(3 \cosh \left(m_{h} L\right)-d \sinh \left(m_{h} L\right)\right) e^{m_{h} L}} \\
C_{3}=\frac{D\left(2\left(9+d^{2}\right)+\left(9-d^{2}\right)\left(e^{-2 m_{h} L}+e^{2 m_{h} L}\right)\right)+18 B e^{-m_{c}(L+g)}+F+24 A(G+H)}{4(G+H)\left((3-d) e^{\left(m_{c}+m_{h}\right) L}+(3+d) e^{\left(m_{c}-m_{h}\right) L}\right)} \\
C_{4}=\frac{\left(-6 A e^{m_{c}(2 L+g)}+D\left((3+d) e^{-m_{h} L}+(3-d) e^{m_{h} L}\right) e^{m_{c} L}+3 B e^{m_{c}(2 L+g)}\left(e^{m_{h} L}+e^{-m_{h} L}\right)\right) e^{2 m_{c}(L+g)}}{(3-d) e^{m_{c}(L+g)+m_{h} L}+(3+d) e^{m_{c}(L+g)-m_{h} L}-(3+d) e^{3 m_{c}(L+g)+m_{h} L}-(3-d) e^{3 m_{c}(L+g)-m_{h} L}}
\end{gathered}
$$

with

$$
\begin{gathered}
A=-\frac{J_{h}^{2} \rho_{0}}{k_{p} m_{h}^{2}} \\
B=\frac{J_{c}^{2} \rho_{0}}{k_{p} m_{c}^{2}}-\frac{J_{h}^{2} \rho_{0}}{k_{p} m_{h}^{2}} \\
D=-\frac{J_{c}^{2} \rho_{0}}{k_{p} m_{c}^{2}} \\
F=-6 A\left((3+d) e^{m_{c} g}+(3-d) e^{-m_{h} L}\right) e^{m_{c}(L+g)}+3 B\left((3+d) e^{-2 m_{h} L}+(3-d) e^{2 m_{h} L}\right) e^{-m_{c}(L+g)} \\
G=\left(3 \cosh \left(m_{h} L\right) \sinh \left(m_{c} g\right)+d \sinh \left(m_{h} L\right) \cosh \left(m_{c} g\right)\right) \cosh \left(m_{c} L\right) \\
H=\left(3 \cosh \left(m_{h} L\right) \cosh \left(m_{c} g\right)+d \sinh \left(m_{h} L\right) \sinh \left(m_{c} g\right)\right) \sinh \left(m_{c} L\right)
\end{gathered}
$$


For the deflection analysis of the actuators, the linear thermal expansion for both upper $\left(\Delta L_{h}\right)$ and bottom $\left(\Delta L_{c}\right)$ beams can be determined as:

$$
\begin{gathered}
\Delta L_{h}=\alpha \int_{0}^{L}\left(T_{h}(s)-T_{0}\right) d s \\
\Delta L_{c}=\alpha \int_{L}^{2 L+g}\left(T_{c}(s)-T_{0}\right) d s
\end{gathered}
$$

where $\alpha$ is the thermal expansion coefficient of polysilicon.

By substituting Equations (8), (9) and (13)-(16) into Equations (23) and (24), the thermal expansions of the upper and bottom beams are given by:

$$
\begin{gathered}
\Delta L_{h}=\alpha\left\{\frac{C_{1}}{m_{h}}\left(e^{m_{h} L}-1\right)-\frac{C_{2}}{m_{h}}\left(e^{-m_{h} L}-1\right)+\frac{J_{h}^{2} \rho_{0} L}{k_{p} m_{h}^{2}}\right\} \\
\Delta L_{c}=\alpha\left\{\frac{C_{3}}{m_{c}}\left[e^{m_{c} L}\left(e^{m_{c}(L+g)}-1\right)\right]-\frac{C_{4}}{m_{c}}\left[e^{-m_{c} L}\left(e^{-m_{c}(L+g)}-1\right)\right]+\frac{J_{c}^{2} \rho_{0}(L+g)}{k_{p} m_{c}^{2}}\right\}
\end{gathered}
$$

The structure of the electrothermal actuator can be considered as a plane rigid frame with two fixed ends. This actuator (see Figure 6) has a statically indeterminate structure with the degree of indeterminacy of $3[35,36]$. The bending moment of the actuator structure due to three unknowns $\left(X_{1}\right.$, $X_{2}$ and $X_{3}$ ) is studied using the force method [35]. These unknowns are internal forces (horizontal force $X_{1}$, vertical force $X_{2}$ and bending moment $X_{3}$ ). The force method will be used to find the redundant unknowns followed by the virtual work method to obtain the deflection at the tip of the frame.

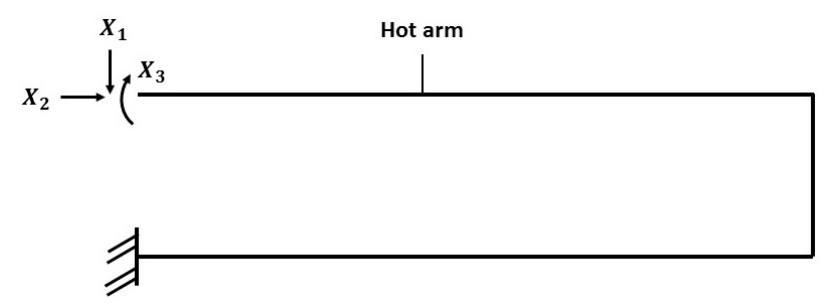

Figure 6. Rigid structure simplified for the electrothermal actuator regarding three redundant forces and moments $\left(X_{1}, X_{2}\right.$ and $\left.X_{3}\right)$.

The three redundants $\left(X_{1}, X_{2}\right.$ and $\left.X_{3}\right)$ are calculated through the canonical equations of the force method, which satisfy the compatibility conditions of the deformations [36]. For this case, the canonical equations are given by the following matrix form:

$$
\left[\begin{array}{lll}
\delta_{11} & \delta_{12} & \delta_{13} \\
\delta_{21} & \delta_{22} & \delta_{23} \\
\delta_{31} & \delta_{32} & \delta_{33}
\end{array}\right]\left[\begin{array}{l}
X_{1} \\
X_{2} \\
X_{3}
\end{array}\right]=\left[\begin{array}{c}
0 \\
\Delta L_{h}-\Delta L_{c} \\
0
\end{array}\right]
$$

where the coefficients $\delta_{i j}$ are called unit displacements that represent the displacements along the direction of unknown $X_{\mathrm{i}}$ caused by action of unit unknown $X_{\mathrm{j}} . \delta_{i j}$ can be determined by the diagram product of the bending moments related with the unit unknowns $X_{\mathrm{i}}$ and $X_{\mathrm{j}}$. These coefficients are obtained as:

$$
\delta_{11}=\frac{L^{2}}{3 E I_{c}}(L+3 g)+\frac{L^{3}}{3 E I_{h}}
$$




$$
\begin{gathered}
\delta_{12}=\delta_{21}=-\frac{L g}{2 E I_{c}}(L+g) \\
\delta_{13}=\delta_{31}=-\frac{L^{2}}{2 E I_{h}}-\frac{L}{2 E I_{c}}(L+2 g) \\
\delta_{22}=\frac{g^{2}}{3 E I_{c}}(g+3 L) \\
\delta_{23}=\delta_{32}=\frac{g}{2 E I_{c}}(g+2 L) \\
\delta_{33}=\frac{L}{E I_{h}}+\frac{1}{E I_{c}}(g+L)
\end{gathered}
$$

where $E$ is the Young's modulus of polysilicon, $I_{h}$ and $I_{c}$ are the moment of inertia of the hot and cold beams, respectively.

Taking at account the method of virtual work, a unit force $F$ is applied to the free end of actuator to calculate the maximum out-of-plane displacement:

$$
\delta_{\max }=\int \frac{M_{F} M}{E I_{h}} d s=\frac{L^{2}}{6 E I_{h}}\left(X_{1} L-3 X_{3}\right)
$$

where $M_{F}$ is the bending moment due to the virtual unit force and $M$ the bending moment related with the thermal expansion. The physical and mechanical properties of the polysilicon used in the above analysis are listed in Table 2.

Table 2. Physical and mechanical properties of the polysilicon beams.

\begin{tabular}{cc}
\hline Property & Value \\
\hline Young's Modulus, $E$ & $169 \mathrm{GPa}$ \\
Thermal expansion, $\alpha$ & $2.5 \times 10^{-6} \mathrm{~K}^{-1}$ \\
Thermal conductivity, $k_{p}$ & $125 \mathrm{~W} \cdot \mathrm{m}^{-1} \cdot \mathrm{K}^{-1}$ \\
Substrate Temperature, $T_{0}$ & $300 \mathrm{~K}$ \\
Linear temperature coefficient, $\xi$ & $1.25 \times 10^{-3} \mathrm{~K}^{-1}$ \\
Resistivity at $T_{0}, \rho_{0}$ & $20.27 \times 10^{-6} \Omega \cdot \mathrm{m}$ \\
Density & $2330 \mathrm{~kg} \cdot \mathrm{m}^{-3}$ \\
Poisson ratio & 0.23 \\
\hline
\end{tabular}

Solving Equation (27), the unknowns $X_{1}, X_{2}$ and $X_{3}$ are the follows:

$$
\begin{aligned}
& X_{1}=\frac{18 E I_{c} I_{h}\left(\Delta L_{h}-\Delta L_{c}\right)\left(I_{h} g+I_{c} L+I_{h} L\right)}{L\left(6 I_{c}^{2} L^{3}+2 I_{c}^{2} L^{2} g+6 I_{c} I_{h} L^{3}+40 I_{c} I_{h} L^{2} g+8 I_{c} I_{h} L g^{2}+2 I_{h}^{2} L^{2} g+17 I_{h}^{2} L g^{2}+3 I_{h}^{2} g^{3}\right)} \\
& X_{2}=\frac{6 E I_{c}\left(\Delta L_{h}-\Delta L_{c}\right)\left(I_{c}^{2} L^{2}+2 I_{c} I_{h} L^{2}+7 I_{c} I_{h} L g+I_{h}^{2} L^{2}+7 I_{h}^{2} L g+6 I_{h}^{2} g^{2}\right)}{g^{2}\left[6 I_{c}^{2} L^{3}+2 I_{c}^{2} L^{2} g+6 I_{c} I_{h} L^{3}+40 I_{c} I_{h} L^{2} g+8 I_{c} I_{h} L g^{2}+2 I_{h}^{2} L^{2} g+17 I_{h}^{2} L g^{2}+3 I_{h}^{2} g^{3}\right]} \\
& X_{3}=\frac{6 E I_{c} I_{h} L\left(\Delta L_{c}-\Delta L_{h}\right)\left(5 I_{h} g-I_{c} g+I_{c} L+I_{h} L\right)}{g\left[6 I_{c}^{2} L^{3}+2 I_{c}^{2} L^{2} g+6 I_{c} I_{h} L^{3}+40 I_{c} I_{h} L^{2} g+8 I_{c} I_{h} L g^{2}+2 I_{h}^{2} L^{2} g+17 I_{h}^{2} L g^{2}+3 I_{h}^{2} g^{3}\right]}
\end{aligned}
$$

Substituting Equations (35) and (36) into Equation (34), we determine the maximum out-of-plane displacement $\left(\delta_{\max }\right)$ of the electrothermal actuator:

$$
\delta_{\max }=\frac{3 I_{c} L^{2}\left(\Delta L_{h}-\Delta L_{c}\right)\left(I_{c} L^{2}+I_{h} L^{2}+I_{h} g^{2}+6 I_{h} L g\right)}{g\left(6 I_{c}^{2} L^{3}+2 I_{c}^{2} L^{2} g+6 I_{c} I_{h} L^{3}+40 I_{c} I_{h} L^{2} g+8 I_{c} I_{h} L g^{2}+2 I_{h}^{2} L^{2} g+17 I_{h}^{2} L g^{2}+3 I_{h}^{2} g^{3}\right)}
$$




\section{Results and Discussions}

This section presents the results of the temperature shift and displacements of the actuator caused by different bias voltages. For this, we considered several variations in the dimensions (width and length) of the actuator.

By using Equations (8), (9) and (38), we determine the temperature and maximum out-of-plane displacement of the electrothermal actuator generated by low dc bias voltages. In this analysis, the initial temperature of the actuator is $20^{\circ} \mathrm{C}$ and the length of each actuator is modified between 350 and $550 \mu \mathrm{m}$. In addition, we regard a variable width (i.e., $w_{h}$ of $2 \mu \mathrm{m}$ to $5 \mu \mathrm{m}$ and $w_{c}$ of $20 \mu \mathrm{m}$ to $30 \mu \mathrm{m}$ ) for the upper and bottom beams and a constant thickness (i.e., $t_{h}=t_{c}=2.25 \mu \mathrm{m}$ ). We compared the results of our models with respect to analytical models of temperature and displacements of electrothermal actuators reported by reference [31]. For this, we use Equations (7), (8) and (23) of reference [31] and assume negligible the flexure beam length (i.e., $L_{f}=0$ ). However, these models are applied for electrothermal actuators of variable cross-section area with in-plane deflections. In order to employ these models to our actuators with out-of-plane deflections, we considered that the variables of width and thickness of their hot and cold beams are equals to the thickness and width of our hot and cold beams. Figure $7 \mathrm{a}, \mathrm{b}$ shows the results of the temperature along of the surface of the upper (hot) and bottom (cold) beams, which are generated by a bias voltage of $2.5 \mathrm{~V}$. This distribution considers different lengths ( 350 and $550 \mu \mathrm{m})$ and two values of width for each upper beam ( 2 and $5 \mu \mathrm{m})$. For all the cases, the maximum temperature is achieved close to the half of the length of the upper beam. The shorter beams present higher temperatures than the larger beams due to their less electrical resistance, which produce higher currents for a bias voltage. For the upper beams of $5 \mu \mathrm{m}$ width, the temperature decays more slowly along of the electrothermal actuator, as shown in Figure $7 \mathrm{~b}$. In the actuator tip, we observed a significant variation in the behavior of the temperature distribution along of the hot and cold beams. The results of our analytical models have a similar behavior respect to those of reference [31]; although, our results register the highest temperature values in all the cases. Next, we calculate the temperature distribution regarding two actuators of different lengths $(450$ and $550 \mu \mathrm{m})$, which are supplied by different dc bias voltages, as shown in Figure $8 \mathrm{a}, \mathrm{b}$. The maximum voltage of $2.5 \mathrm{~V}$ generates the higher temperature magnitudes $\left(147.3{ }^{\circ} \mathrm{C}\right.$ and $\left.114.9^{\circ} \mathrm{C}\right)$ for both actuators, considering our models. For the actuator of $450 \mu \mathrm{m}$ length, the bias voltages of $1.0 \mathrm{~V}, 1.5 \mathrm{~V}$ and 2.0 $\mathrm{V}$ increase the temperature up $38.2{ }^{\circ} \mathrm{C}, 62.1{ }^{\circ} \mathrm{C}$ and $97.6^{\circ} \mathrm{C}$, respectively. For the same voltages, the actuator of $550 \mu \mathrm{m}$ length has an increment of temperature of $34.0^{\circ} \mathrm{C}, 52.0^{\circ} \mathrm{C}$ and $78.5^{\circ} \mathrm{C}$, respectively. Also, the temperature distribution along the actuator of $450 \mu \mathrm{m}$ length was determined varying the width of the upper and bottom beams, as shown in Figure 9a,b. For upper beams of $2 \mu \mathrm{m}$ width and bias voltage of $2.5 \mathrm{~V}$, the temperature has a low increment of $16.6^{\circ} \mathrm{C}$ when the width of the bottom beam increases from 20 to $30 \mu \mathrm{m}$. Instead, the temperature distribution decays more slowly for upper beams of $5 \mu \mathrm{m}$ width, keeping $30 \mu \mathrm{m}$ width for the bottom beam. For these cases, the results of our models have good agreement respect to those of reference [31].

Figure 10a,b depicts the maximum out-of-plane displacements of the actuator tip as a function of bias voltage and assuming different length and width values. For these cases and considering $2.5 \mathrm{~V}$, the beam of $550 \mu \mathrm{m}$ length has the larger displacements $(10.3 \mu \mathrm{m}$ and $6.8 \mu \mathrm{m})$ when $w_{h}=2 \mu \mathrm{m}$ and $w_{c}=30 \mu \mathrm{m}$, respectively. These displacements have direction down due to the higher temperature of the upper beams. However, if the position of the beams is inverted then the motion of the actuator will be upward. If the length of the actuator is $450 \mu \mathrm{m}$ and the bias voltage is $2.5 \mathrm{~V}$ then the maximum displacements are $8.9 \mu \mathrm{m}$ and $5.6 \mu \mathrm{m}$, respectively. The response of our models has good agreement respect to results of reference [31]. Although the displacements obtained with our analytical models have higher values than those of the reference [31]. Figure 11a,b shows the maximum out-of-plane displacements of the actuator ( $450 \mu \mathrm{m}$ length and $2.5 \mathrm{~V}$ voltage) considering different dimensions in the width of its upper and bottom beams. For these cases, the larger displacement $(8.9 \mu \mathrm{m})$ is obtained with $2.5 \mathrm{~V}$ voltage for beams with $w_{h}=2 \mu \mathrm{m}$ and $w_{c}=30 \mu \mathrm{m}$, respectively. In addition, the displacement of the actuator tip decreases when the width of the upper beams increases. Moreover, if the width 
of the bottom beam increases then the actuator tip will have larger displacements. The electrical power of each actuator is determined using the equivalent electrical circuit of Figure 5. For an actuator with $w_{h}=2 \mu \mathrm{m}, w_{c}=30 \mu \mathrm{m}$ and three different lengths $L_{h}: 350 \mu \mathrm{m}, 450 \mu \mathrm{m}$ and 550, we obtain the following electrical power: $9.9 \mathrm{~mW}, 7.7 \mathrm{~mW}$ and $6.3 \mathrm{~mW}$. Finally, the displacements of the actuator tip can be increased with bias voltages higher than $2.5 \mathrm{~V}$, which also will increment the electrical power. For instance, if the actuator of $L_{h}=550 \mu \mathrm{m}$ and $w_{h}=2 \mu \mathrm{m}$ is biased with $5 \mathrm{~V}$ then its maximum displacement, temperature and power are increased up $59.2 \mu \mathrm{m}, 570.3^{\circ} \mathrm{C}$ and $25.2 \mathrm{~mW}$, respectively. Furthermore, the mirror surface area can be scalable to achieve larger values than $10000 \mu \mathrm{m}^{2}$. On the other hand, the surface of the silicon substrate below of the actuators array and mirror must be etched using DRIE process to allow the free motion of the actuators and mirror under different bias voltages. Nevertheless, the maximum displacement of the actuators must generate stress less than the rupture stress of the polysilicon.

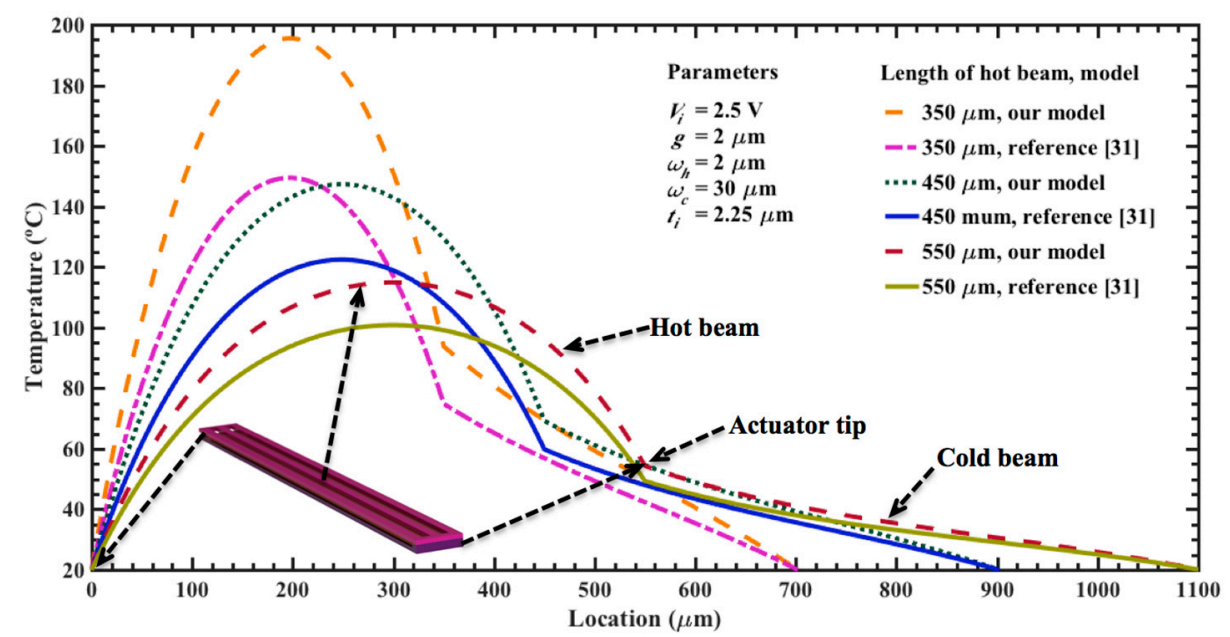

(a)

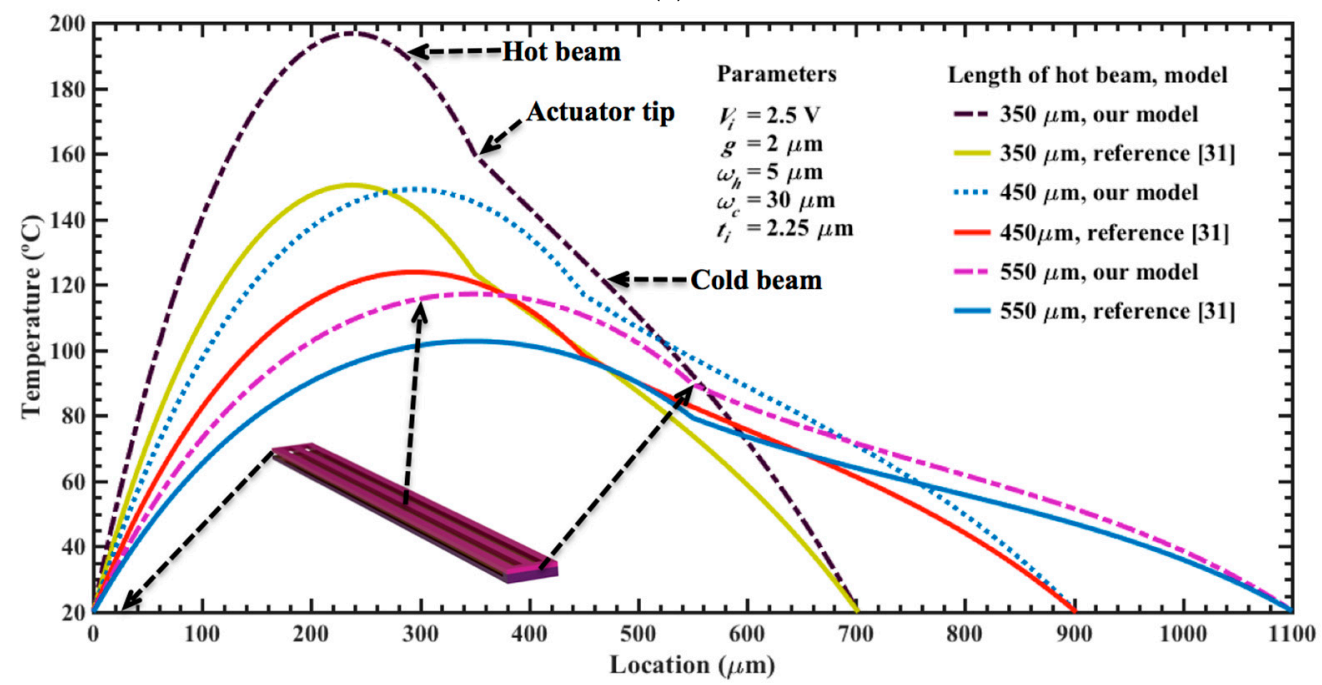

(b)

Figure 7. Distribution of the temperature along of the upper (hot) and bottom (cold) beams of an electrothermal actuator, which considers different lengths $(350 \mu \mathrm{m}$ to $550 \mu \mathrm{m})$ and two width values for the upper beams: (a) $2 \mu \mathrm{m}$; and (b) $5 \mu \mathrm{m}$. 


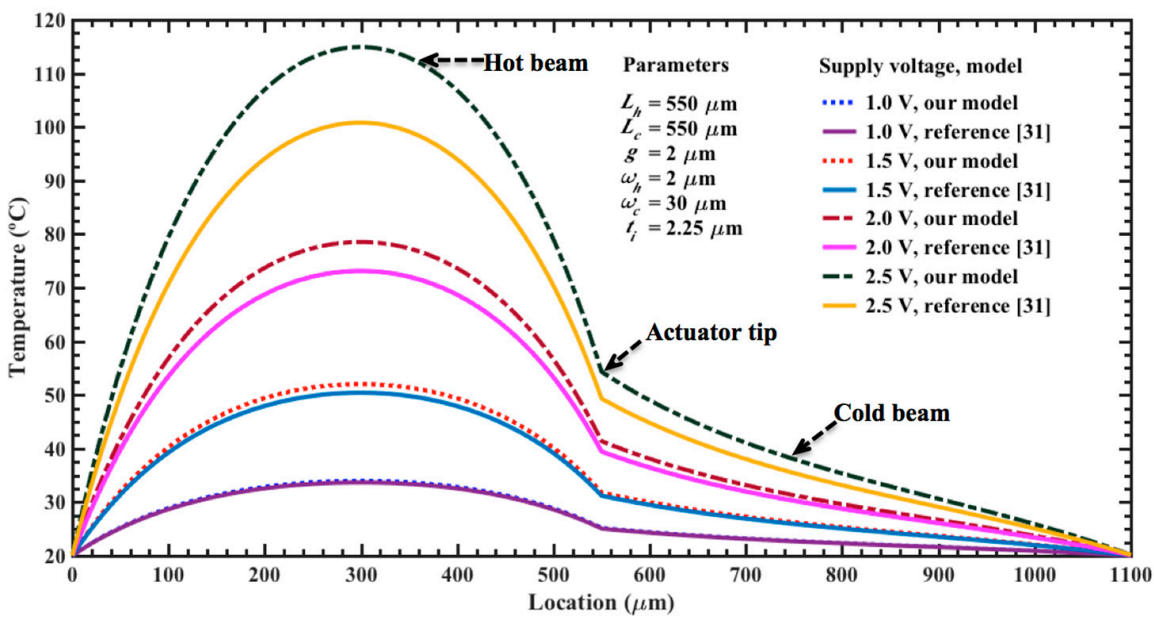

(a)

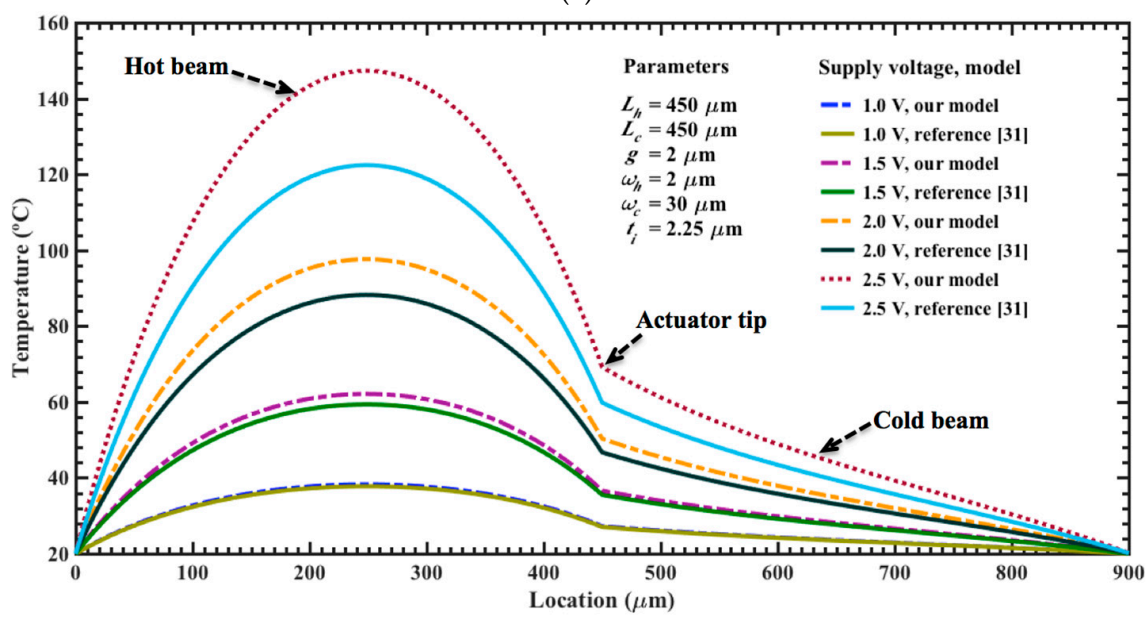

(b)

Figure 8. Distribution of the temperature along of the upper (hot) and bottom (cold) beams of two electrothermal actuators with lengths of (a) $550 \mu \mathrm{m}$ and (b) $450 \mu \mathrm{m}$. This temperature is due to different bias voltages, whose values change from 0.5 to $2.5 \mathrm{~V}$.

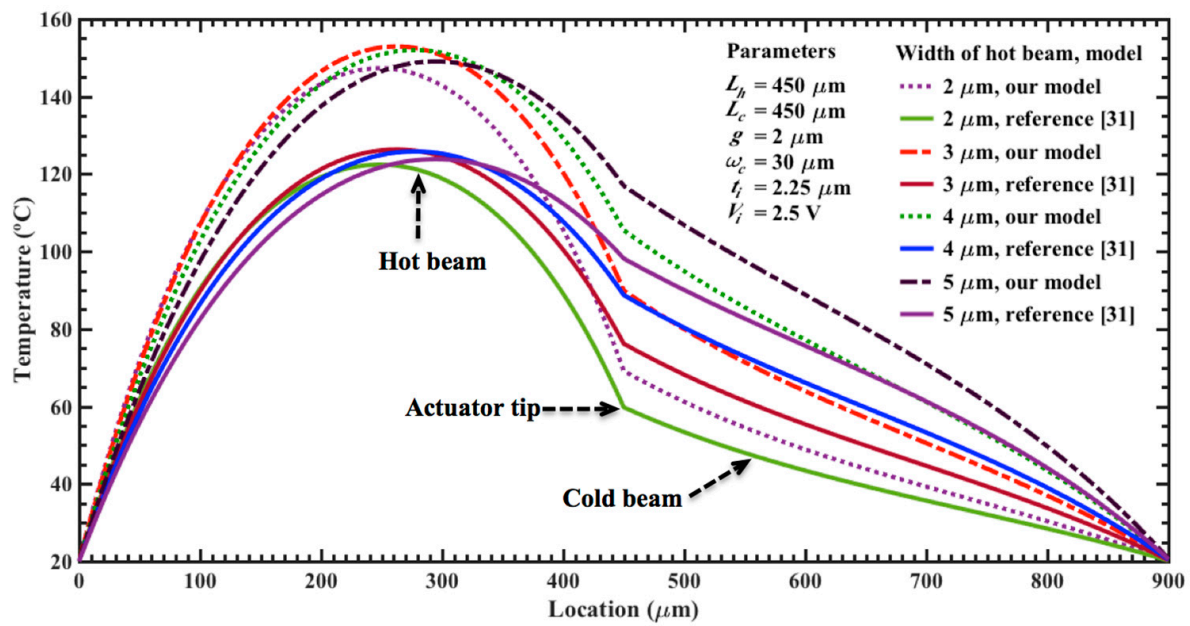

(a)

Figure 9. Cont. 


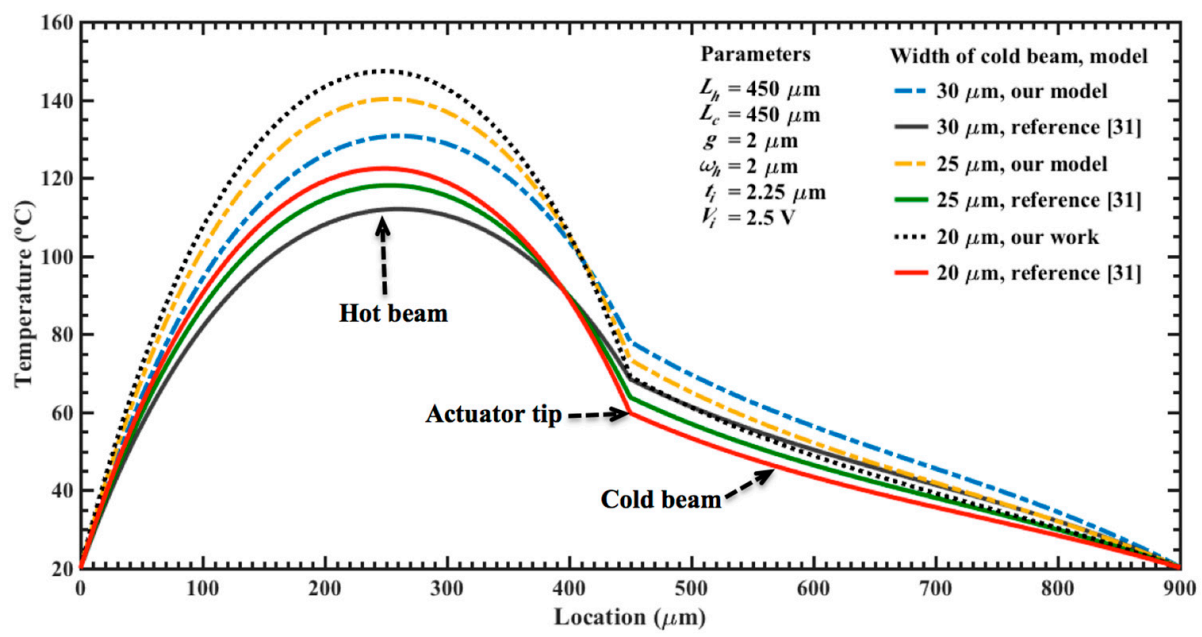

(b)

Figure 9. Distribution of the temperature along of the upper (hot) and bottom (cold) beams of an electrothermal actuator, modifying the width of the (a) upper and (b) bottom beams. For both cases, the length of the actuator is $450 \mu \mathrm{m}$ and bias voltage is $2.5 \mathrm{~V}$, respectively.

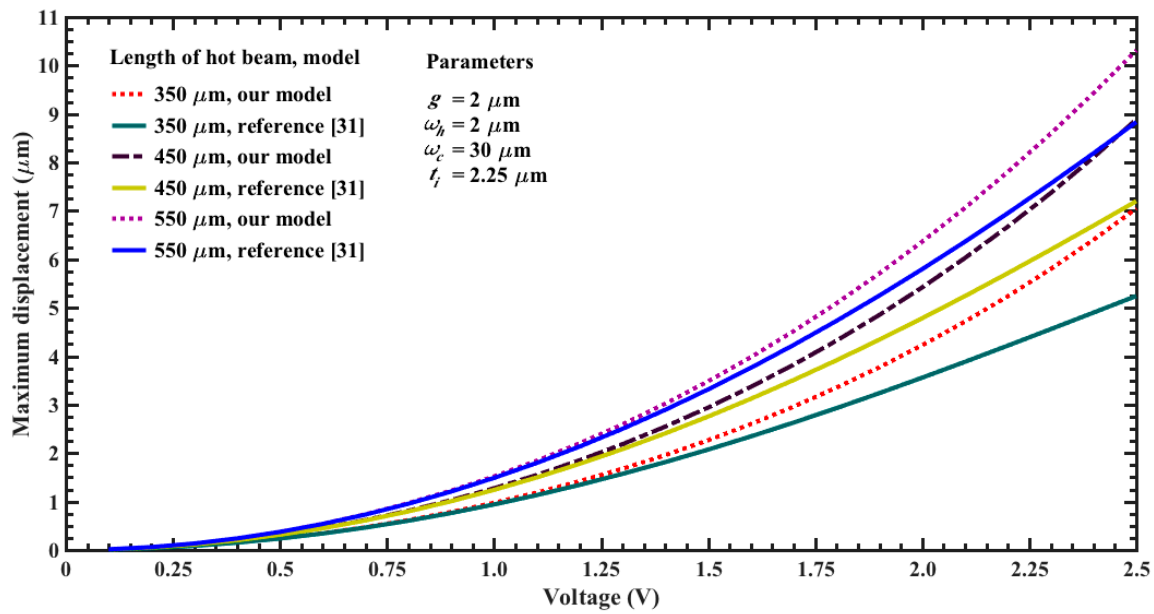

(a)

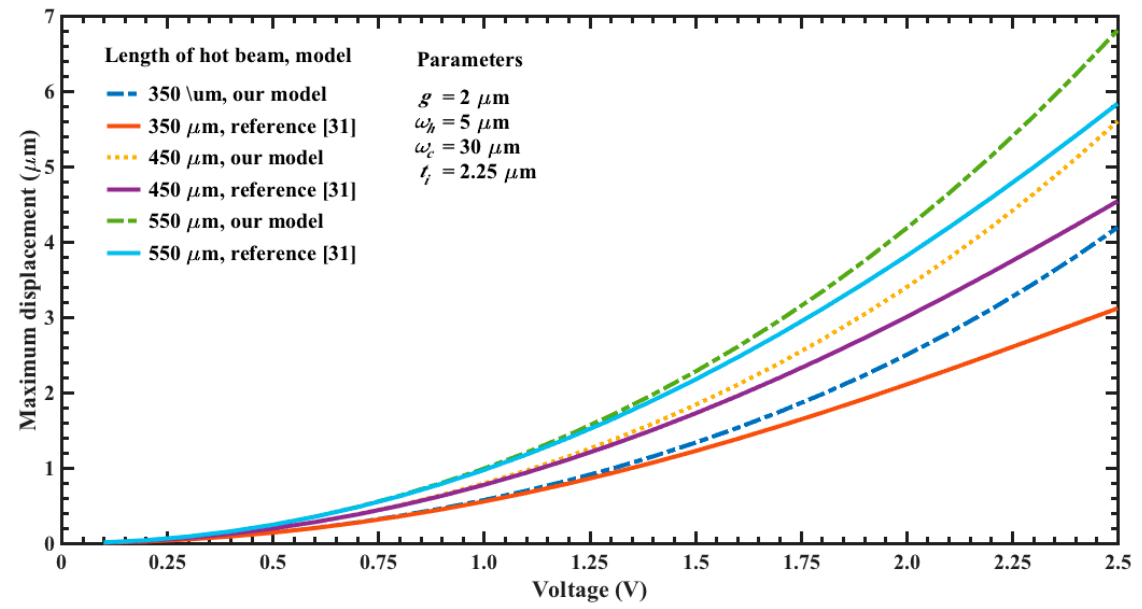

(b)

Figure 10. Maximum out-of-plane displacements of the electrothermal actuator tip as a function of bias voltage, regarding different lengths and two width values for the upper beams: (a) $2 \mu \mathrm{m}$ and (b) $5 \mu \mathrm{m}$. 


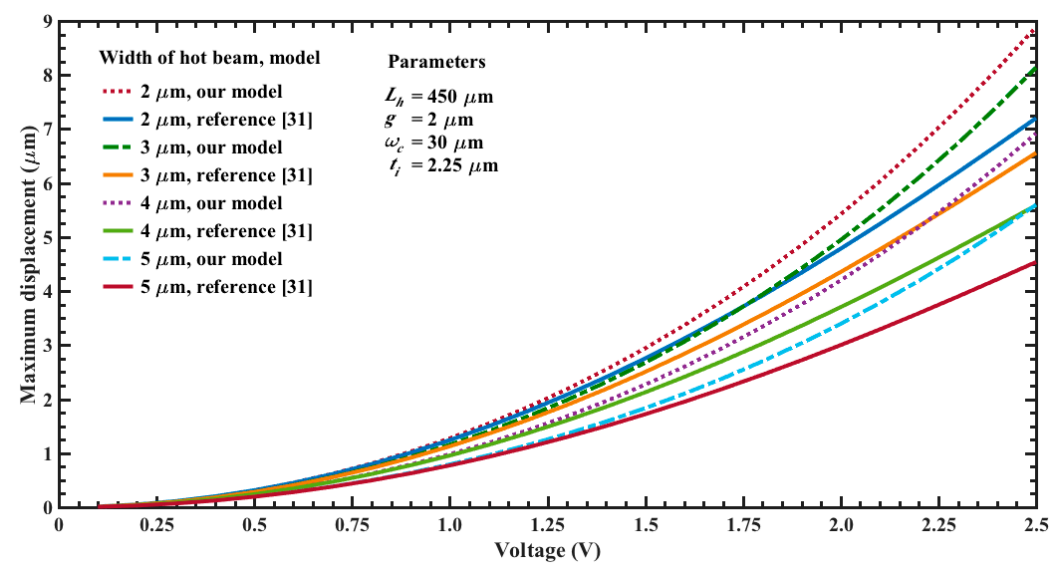

(a)

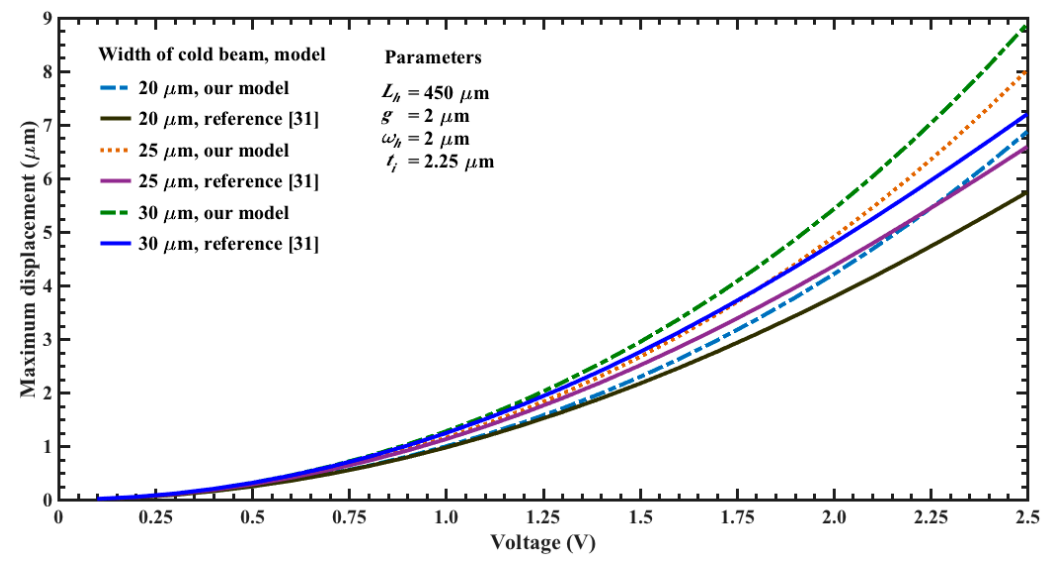

(b)

Figure 11. Maximum out-of-plane displacements of the electrothermal actuator tip as a function of bias voltage, varying the width of the (a) upper and (b) bottom beams. For both cases, the length of the actuator is $450 \mu \mathrm{m}$ and bias voltage is $2.5 \mathrm{~V}$, respectively.

Finally, we developed finite elements method (FEM) models using the ANSYS ${ }^{\circledR}$ software (version 15.0, ANSYS, Berkeley, CA, USA) to predict the out-of-plane displacements of the proposed actuation mechanism. For this, the pads were negligible and the initial end of each actuator was considered as fixed support. For these supports were applied a bias voltage of $2.5 \mathrm{~V}$ and initial temperature of $20{ }^{\circ} \mathrm{C}$. The FEM models regard polysilicon actuators with the following dimensions: $L_{h}=L_{c}=550 \mu \mathrm{m}$, $\omega_{h}=2 \mu \mathrm{m}, \omega_{c}=30 \mu \mathrm{m}, t_{i}=2.25 \mu \mathrm{m}$ and $g=2 \mu \mathrm{m}$. Our FEM models include elements solid226 type with a hexahedral mesh. First, we use a FEM model of a single electrothermal actuator under $2.5 \mathrm{~V}$ bias voltage. Figure 12 depicts the out-of-plane displacements of this actuator, achieving a maximum downward deflection of $10.3 \mu \mathrm{m}$ that well agree with the results $(10.3 \mu \mathrm{m}$ and $8.8 \mu \mathrm{m})$ of both our analytical model and that of the reference [31], as shown in Figure 10a. Next, we used a FEM model composed by four polysilicon electrothermal actuators, four springs $(508 \mu \mathrm{m}$ length, $5 \mu \mathrm{m}$ width and $2.25 \mu \mathrm{m}$ thickness) and a mirror. Each one of these actuators has the same dimension respect to the previous actuator. The initial ends of the four actuators have boundary conditions of clamped support and temperature of $20^{\circ} \mathrm{C}$. For this FEM model, we studied four different cases modifying the bias voltage values of the four actuators. For the first case, one actuator was only supplied with a voltage of $2.5 \mathrm{~V}$, keeping the other three actuators without bias voltage (see Figure 13). Thus, the actuator and mirror have maximum out-of-plane deflections of $7.4 \mu \mathrm{m}$ and $4.8 \mu \mathrm{m}$, respectively. For this case, the displacement of the actuator decreases $(3.9 \mu \mathrm{m})$ respect the response of a single actuator without connection with springs and mirror. This displacement reduction is due to an increment of the model stiffness when the four actuators are joined to the mirror. In the second case two actuators are biased 
with $2.5 \mathrm{~V}$, obtaining out-of-plane displacements with opposite directions (downward and upward) that allow the mirror rotation with respect to two of its vertices, as shown in Figure 14. The absolute value of the maximum displacement of the two biased actuators is $6.7 \mu \mathrm{m}$, which is $3.5 \mu \mathrm{m}$ less than that obtained with a single actuator. Two mirror vertices reach maximum displacements of $3.7 \mu \mathrm{m}$ and $-3.7 \mu \mathrm{m}$, respectively. For the third case, a $2.5 \mathrm{~V}$ bias voltage is applied for three actuators, achieving maximum displacements of $9.2 \mu \mathrm{m}, 7.7 \mu \mathrm{m}$ and $-4.5 \mu \mathrm{m}$ (see Figure 15). Indeed, two mirror vertices have displacements of $6.2 \mu \mathrm{m}$ and $-1.4 \mu \mathrm{m}$ that enable the mirror tilting. In the last case all the actuators are biased with $2.5 \mathrm{~V}$, obtaining the downward and upward deflection of two actuator pairs as well as the mirror rotation along the $x$-axis (see Figure 16). The larger displacements of the actuators and mirror are $7.1 \mu \mathrm{m},-7.1 \mu \mathrm{m}, 3.9$ and $-3.9 \mu \mathrm{m}$, respectively. In order to reach larger deflection and tilting of the actuators and mirror, the bias voltage can be increased. Moreover, the rotation orientation of the mirror can be regulated through the selective biasing of the four actuators. Also, the proposed actuation mechanism can be employed for MEMS mirrors of larger surface area and their rotation angles can be controlled using different bias voltages.

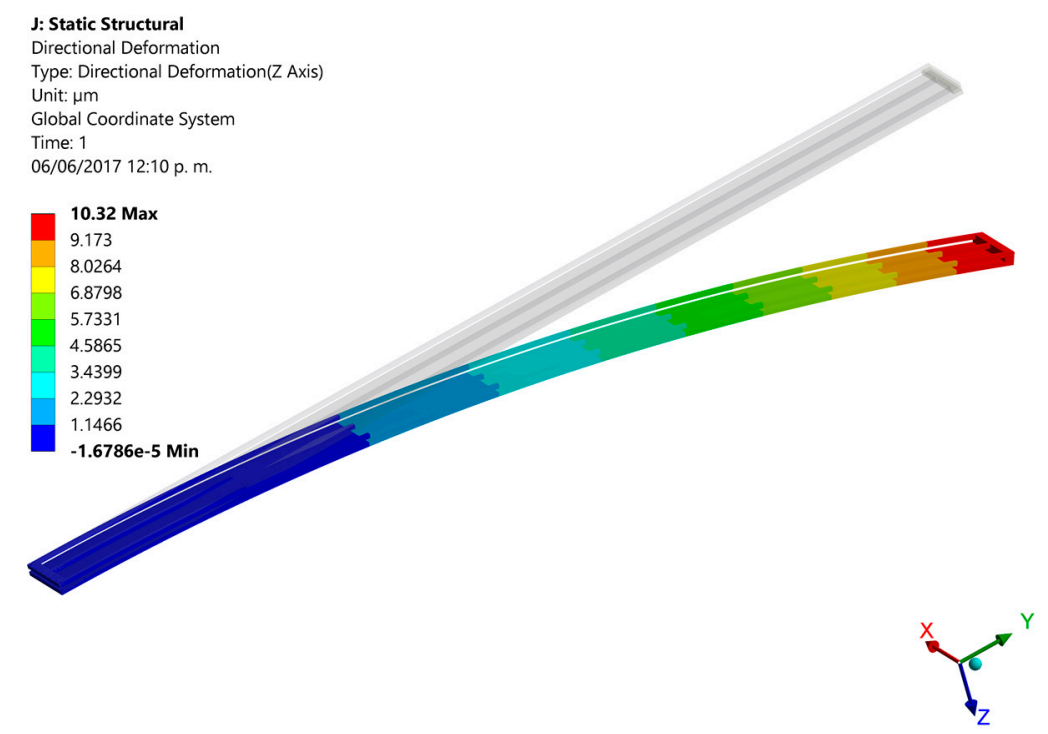

Figure 12. Out-of-plane displacements of one polysilicon electrothermal actuator $\left(L_{h}=L_{c}=550 \mu \mathrm{m}\right)$ caused by a $2.5 \mathrm{~V}$ bias voltage.

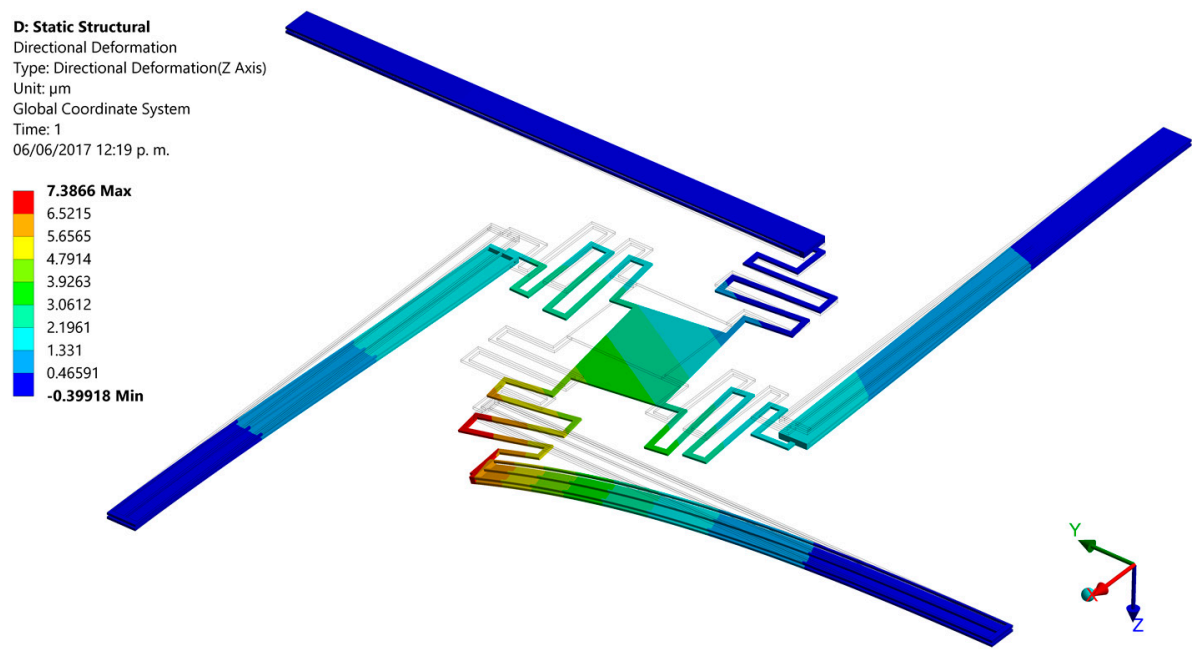

Figure 13. Out-of-plane deflections of the MEMS mirror when one polysilicon electrothermal actuator $\left(L_{h}=L_{c}=550 \mu \mathrm{m}\right)$ is biased with $2.5 \mathrm{~V}$. 


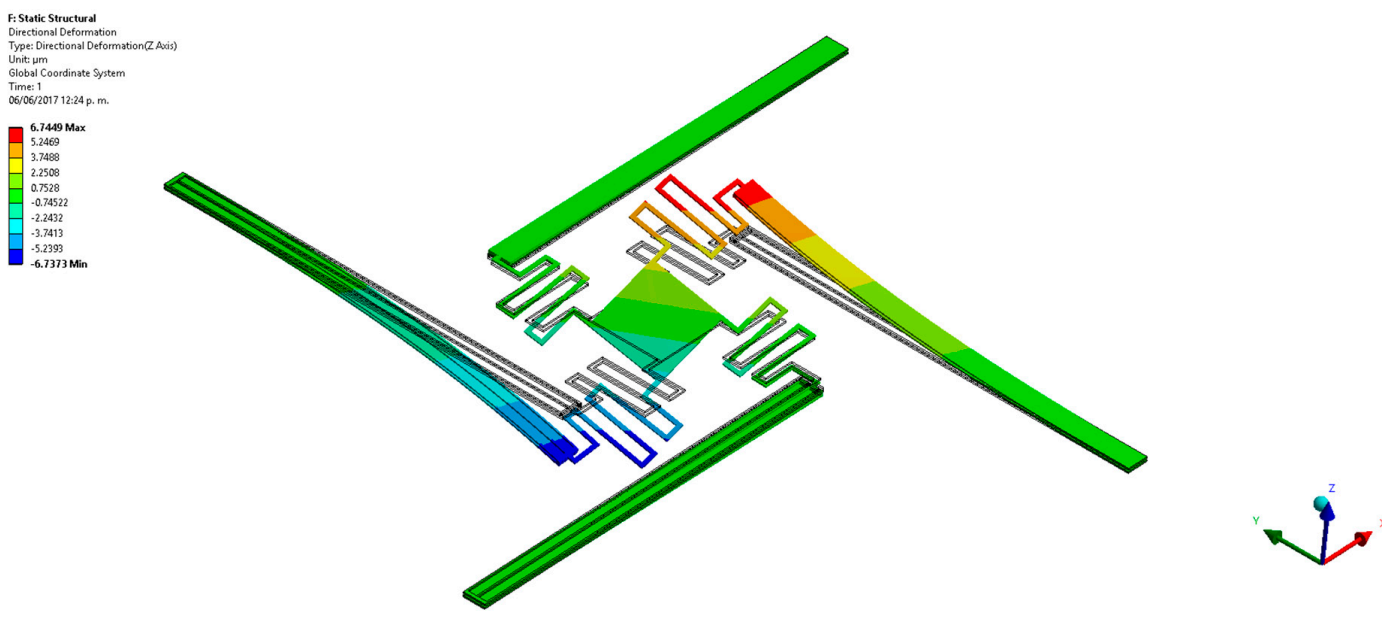

Figure 14. Out-of-plane displacements of the MEMS mirror when two polysilicon electrothermal actuators $\left(L_{h}=L_{c}=550 \mu \mathrm{m}\right)$ are biased with $2.5 \mathrm{~V}$.

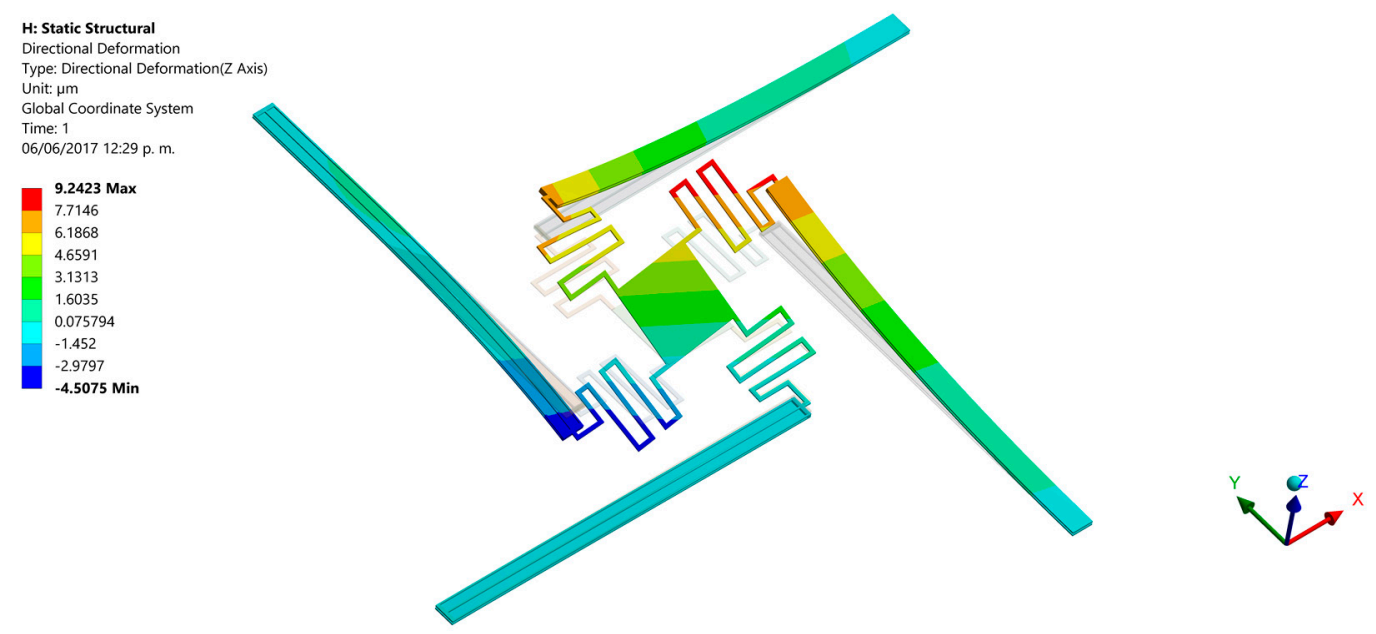

Figure 15. Out-of-plane displacements of the MEMS mirror when three polysilicon electrothermal actuators $\left(L_{h}=L_{c}=550 \mu \mathrm{m}\right)$ are biased with $2.5 \mathrm{~V}$.

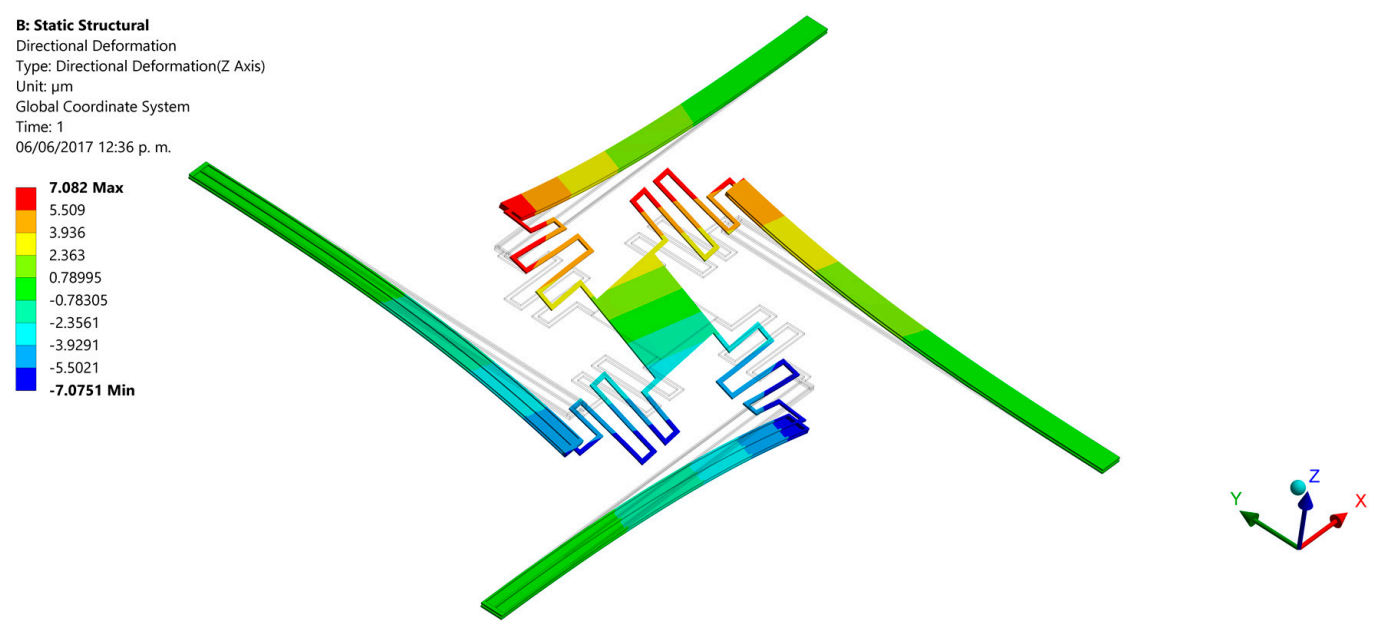

Figure 16. Out-of-plane displacements of the MEMS mirror when four polysilicon electrothermal actuators $\left(L_{h}=L_{\mathcal{C}}=550 \mu \mathrm{m}\right)$ are biased with $2.5 \mathrm{~V}$. 
Table 3 depicts the characteristics of several MEMS mirrors that use electrothermal actuators. Based on these devices, our design provides an easy actuation mechanism that does not require materials layers with different thermal expansion coefficients. It can simplify the actuators fabrication process and reduce the thermal residual stresses due to the fabrication. The proposed design is based on SUMMiT V process, which improves the flatness of the structures and minimize thermal residual strains. Indeed, our design has a minimum footprint size $(1028 \times 1028)$ and mirror surface area $(100 \mu \mathrm{m} \times 100 \mu \mathrm{m})$, achieving different rotation orientations of the mirror that are well controlled using reduced bias voltages. Most of the other designs need different metallic films (e.g., $\mathrm{Al}, \mathrm{Cu}, \mathrm{W}$ or $\mathrm{Pt}$ ) deposited on the actuators by sputtering process, which can generate initial thermal strains (i.e., initial displacement offset) that can affect the actuators performance. Indeed, our actuation mechanism can be adjusted for MEMS mirrors with larger surface area than 10,000 $\mathrm{m}^{2}$, which can be suitable for potential applications in endoscopic OCT systems.

Table 3. Characteristics of several MEMS mirrors based on electrothermal actuators.

\begin{tabular}{ccccc}
\hline Authors & Mirror Size & $\begin{array}{c}\text { Device Footprint } \\
(\mu \mathrm{m} \times \boldsymbol{\mu m})\end{array}$ & $\begin{array}{c}\text { Maximum } \\
\text { Displacement }(\boldsymbol{\mu m})\end{array}$ & $\begin{array}{c}\text { Bias Voltage } \\
(\mathbf{V})\end{array}$ \\
\hline Zhang et al. [18] & $900 \mu \mathrm{m} \times 900 \mu \mathrm{m}$ & $2500 \times 2500$ & 312 & 3 \\
Kawai et al. [37] & $3000 \mu \mathrm{m}$ diameter & $5000 \times 5000$ & $*_{-}$ & 20 \\
Zhang et al. [38] & $1000 \mu \mathrm{m} \times 1000 \mu \mathrm{m}$ & $1500 \times 1500$ & 70 & 2 \\
Li et al. [39] & $1000 \mu \mathrm{m}$ diameter & $2000 \times 2000$ & 227 & 0.8 \\
Espinosa et al. [40] & $1000 \mu \mathrm{m} \times 1000 \mu \mathrm{m}$ & $1500 \times 1500$ & 174 & 3.5 \\
Koh et al. [41] & $1500 \mu \mathrm{m} \times 1000 \mu \mathrm{m}$ & $6000 \times 6000$ & $*$ & 5 \\
Our work & $100 \mu \mathrm{m} \times 100 \mu \mathrm{m}$ & $1028 \times 1028$ & 59.2 & 5 \\
\hline
\end{tabular}

*- Data not available in literature.

\section{Conclusions}

The design and modeling of an electrothermal actuation mechanism for a polysilicon mirror $(100 \mu \mathrm{m} \times 100 \mu \mathrm{m} \times 2.25 \mu \mathrm{m})$ was developed. These actuators were designed based on the SUMMiT V surface micromachining process from Sandia National Laboratories. The actuators are composed by two polysilicon structural layers, which are vertically separated by $2 \mu \mathrm{m}$. The temperature and out-of-plane displacements of the actuators were determined using electrothermal and structural models and assuming the polysilicon resistivity as a function of temperature. The electrothermal models included the rate of heat energy generation, heat conduction and heat energy loss. On the other hand, the structural model was obtained with the force method and assuming low dc voltages $(0.5 \mathrm{~V}$ to $2.5 \mathrm{~V})$. For actuators with lengths of 450 and $550 \mu \mathrm{m}$, the higher temperatures and out-of-plane displacements generated by $2.5 \mathrm{~V}$ are: $147.3^{\circ} \mathrm{C}, 115^{\circ} \mathrm{C}, 8.9 \mu \mathrm{m}$ and $10.3 \mu \mathrm{m}$, respectively. These actuators can have upward and downward motion if their structural layers are inverted. Thus, the mirror tilting can be controlled modifying the position of the structural layers and altering the actuators dimensions and magnitudes of the dc bias voltages. In addition, the device footprint size is $1028 \mu \mathrm{m} \times 1028 \mu \mathrm{m}$ considering electrothermal actuators of $550 \mu \mathrm{m}$ length. With a bias voltage of $2.5 \mathrm{~V}$, the electrical power for an actuator of $550 \mu \mathrm{m}$ length was $6.3 \mathrm{~mW}$. The proposed actuation mechanism could be used to obtain the rotation of MEMS mirrors with different surface area. The rotation orientation of the mirrors can be modified through the selective biasing of the actuators. This actuation mechanism for MEMS mirrors could be considered for potential applications in endoscopic OCT systems.

Future researches will include the fabrication and characterization of several electrothermal actuators array for MEMS mirrors with different surface area using the SUMMiT V process.

Acknowledgments: The work was partially supported by the MEMS University Alliance Program of Sandia National Laboratories, CONACYT and FORDECYT-CONACYT through grants 48757 and 115976, project PROINNOVA "Ecoplataforma biomimética para agricultura de precision aplicando micro/nanotecnología" through grant 231500 and projects PRODEP “Estudio de Dispositivos Electrónicos y Electromecánicos 
con Potencial Aplicación en Fisiología y Optoelectrónica” and PFCE “2016-2017 DES Técnica Veracruz P/PFCE-2017-30MSU0940B-22".

Author Contributions: Miguel Lara-Castro, Adrian Herrera-Amaya, Francisco López-Huerta and Agustín L. Herrera-May develop the design and modeling of the electrothermal actuators for a MEMS mirror. Moisés Vazquez-Toledo and Marco A. Escarola-Rosas made the layout of the actuators using the SUMMiT V fabrication process. Adrian Herrera-Amaya, Francisco López-Huerta, Luz A. Aguilera-Cortés and Agustín L. Herrera-May wrote all the sections of the paper.

Conflicts of Interest: The authors declare no conflict of interest.

\section{References}

1. Chang, C.I.; Tsai, M.H.; Liu, Y.C.; Sun, C.M.; Fang, W. Pick-and-place process for sensitivity improvement of the capacitive type CMOS MEMS 2-axis tilt sensor. J. Micromech. Microeng. 2013, 23, 095029. [CrossRef]

2. Juárez-Aguirre, R.; Domínguez-Nicolás, S.M.; Manjarrez, E.; Tapia, J.A.; Figueras, E.; Vázquez-Leal, H.; Aguilera-Cortés, L.A.; Herrera-May, A.L. Digital Signal Processing by Virtual Instrumentation of a MEMS Magnetic Field Sensor for Biomedical Applications. Sensors 2013, 13, 15068-15084. [CrossRef] [PubMed]

3. Huang, J.Q.; Li, F.; Zhao, M.; Wang, K.A. Surface Micromachined CMOS MEMS Humidity Sensor. Micromachines 2015, 6, 1569-1576. [CrossRef]

4. Hung, A.C.-L.; Lai, H.Y.-H.; Lin, T.-W.; Fu, S.-G.; Lu, M.S.-C. An electrostatically driven 2D micro-scanning mirror with capacitive sensing for projection display. Sens. Actuators A 2015, 222, 122-129. [CrossRef]

5. Liu, Y.; Xu, J.; Zhong, S.; Wu, Y. Large size MEMS scanning mirror with vertical comb drive for tunable optical filter. Opt. Lasers Eng. 2013, 51, 54-60. [CrossRef]

6. Holmström, S.T.S.; Baran, U.; Urey, H. MEMS laser scanners: A review. J. Microelectromech. Syst. 2014, 23, 259-275. [CrossRef]

7. Wang, W.; Chen, J.; Zivkovic, A.S.; Tanguy, Q.A.A.; Xie, H. A compact Fourier transform spectrometer on a silicon optical bench with an electrothermal MEMS mirror. J. Microelectromech. Syst. 2016, 25, 347-355. [CrossRef]

8. Liu, L.; Wang, E.; Zhang, X.; Liang, W.; Li, X.; Xie, H. MEMS-based 3D confocal scanning microendoscope using MEMS scanner for both lateral and axial scan. Sens. Actuators A 2014, 215, 89-95. [CrossRef] [PubMed]

9. Liu, L.Y.; Keeler, E.G. Progress of MEMS scanning micromirrors for optical bio-imaging. Micromachines 2015, 6, 1675-1689.

10. Haindl, R.; Trasischker, W.; Baumann, B.; Pircher, M.; Hitzenberger, C.K. Three-beam Doppler optical coherence tomography using a facet prism telescope and MEMS mirror for improved transversal solution. J. Mod. Opt. 2015, 62, 1781-1788. [CrossRef] [PubMed]

11. Jung, W.; McCormick, D.; Ahn, Y.; Sepehr, A.; Brenner, M.; Wong, B.; Tien, N.; Chen, Z. In vivo tree-dimensional spectral domain endoscopic optical coherence tomography using a microelectromechanical system mirror. Opt. Lett. 2007, 32, 3239-3241. [CrossRef] [PubMed]

12. Jung, W.; McCormick, D.T.; Zhang, J.; Wang, L.; Tien, N.C.; Chen, Z. Three-dimensional endoscopic optical coherence tomography by use of a two-axis microelectromechanical scanning mirror. Appl. Phys. Lett. 2006, 88,163901 . [CrossRef]

13. Solgaard, O.; Godil, A.A.; Howe, R.T.; Lee, L.P.; Peter, Y.-A.; Zappe, H. Optical MEMS: From micromirrors to complex systems. J. Microelectromech. Syst. 2014, 23, 517-535. [CrossRef]

14. Kim, J.-H.; Jeong, H.; Lee, S.-K.; Ji, C.-H.; Park, J.-H. Electromagnetically actuated biaxial scanning micromirror fabricated with silicon on glass wafer. Microsyst. Technol. 2017, 23, 2075-2085. [CrossRef]

15. Cho, A.R.; Han, A.; Ju, S.; Jeong, H.; Park, J.-H.; Kim, I.; Bu, J.-U.; Ji, C.-J. Electromagnetic biaxial microscanner with mechanical amplification at resonance. Opt. Express 2015, 23, 16792-16802. [CrossRef] [PubMed]

16. Fan, C.; He, S. A microelectrostatic repulsive-torque rotation actuator with-width finger. J. Micromech. Microeng. 2015, 25, 095006. [CrossRef]

17. Zhang, X.; Duan, C.; Liu, L.; Li, X.; Xie, H. A non-resonant fiber scanner based on a electrothermally-actuated MEMS stage. Sens. Actuators A 2015, 233, 239-245. [CrossRef] [PubMed]

18. Zhang, X.; Zhou, L.; Xie, H. A fast, large-stroke electrothermal MEMS mirror based on Cu/W bimorph. Micromachines 2015, 6, 1876-1889. [CrossRef]

19. Naono, T.; Fujii, T.; Esashi, M.; Tanaka, S. Non-resonant 2-D piezoelectric MEMS optical scanner actuated by $\mathrm{Nb}$ doped PZT thin film. Sens. Actuators A 2015, 233, 147-157. [CrossRef] 
20. Chen, C.D.; Lee, Y.H.; Yeh, C.S. Design and vibration analysis of a piezoelectric-actuated MEMS scanning mirror and its application to laser projection. Smart Mater. Struct. 2014, 23, 125007. [CrossRef]

21. Jung, W.; Tang, S.; McCormick, D.T.; Xie, T.; Anh, Y.-C.; Su, J.; Tomov, I.V.; Krasieva, T.B.; Tromberg, B.J.; Chen, Z. Miniaturized probe based on a microelectromechanical system mirror for multiphoton microscopy. Opt. Lett. 2008, 33, 1324-1326. [CrossRef] [PubMed]

22. Sun, J.; Guo, S.; Wu, L.; Liu, L.; Choe, S.-W.; Sorg, B.S.; Xie, H. 3D in vivo optical coherence tomography based on a low-voltage, large-scan-range 2D MEMS mirror. Opt. Express 2010, 18, 12065. [CrossRef] [PubMed]

23. Bauer, R.; Li, L.; Uttamchandani, D. Dynamic properties of angular vertical comb-drive scanning micromirros with electrothermally controlled variable offset. J. Microelectromech. Syst. 2014, 23, 999-1008. [CrossRef]

24. Li, F.; Zhou, P.; Wang, T.; He, J.; Yu, H.; Shen, W. A large-size MEMS scanning mirror for speckle reduction application. Micromachines 2017, 8, 140. [CrossRef]

25. Ataman, C.; Lani, S.; Noell, W.; de Rooij, N. A dual-axis pointing mirror with moving-magnet actuation. J. Micromech. Microeng. 2013, 23, 025002. [CrossRef]

26. Choi, Y.-M.; Gorman, J.J.; Dagalakis, N.G.; Yang, S.H.; Kim, Y.; Yoo, J.M. A high-bandwidth electromagnetic MEMS motion stage for scanning applications. J. Micromech. Microeng. 2012, 22, 105012. [CrossRef]

27. Koh, K.H.; Kobayashi, T.; Lee, C. Investigation of piezoelectric driven MEMS mirrors based on single and double S-shaped PZT actuator for 2-D scanning applications. Sens. Actuators A 2012, 184, 149-159. [CrossRef]

28. Duan, C.; Wang, D.; Zhou, Z.; Liang, P.; Samuelson, S.; Pozzi, A.; Xie, H. Swept-source common-path optical coherence tomography with a MEMS endoscopic imaging probe. In Proceedings of the SPIE Optical Coherence Tomography and Coherence Domain Optical Methods Biomedicine XVIII, San Francisco, CA, USA, 3-5 February 2014; Volume 8934. [CrossRef]

29. Samuelson, S.R.; Xie, H. A large piston displacement MEMS mirror with electrothermal ladder actuator arrays for ultra-low tilt applications. J. Microelectromech. Syst. 2014, 23, 39-49. [CrossRef]

30. Koh, K.H.; Lee, C. A two-dimensional MEMS scanning mirror using hybrid actuation mechanisms with low operation voltage. J. Microelectromech. Syst. 2012, 21, 1124-1135. [CrossRef]

31. Huang, Q.A.; Lee, N.K.S. Analysis and design of polysilicon thermal flexure actuator. J. Micromech. Microeng. 1999, 9, 64-70. [CrossRef]

32. Torres, D.; Wang, T.; Zhang, J.; Zhang, X.; Dooley, S.; Tan, X.; Xie, H.; Sepúlveda, N. VO2-based MEMS mirrors. J. Microelectromech. Syst. 2016, 780-787. [CrossRef]

33. Sandia National Laboratories. Available online: http://www.sandia.gov/mstc/_assets/documents/design_ documents/SUMMiT_V_Dmanual.pdf (accessed on 3 June 2016).

34. Lin, L.; Chiao, M. Electrothermal responses of lineshape microstructures. Sens. Actuators A 1996, 55, 35-41. [CrossRef]

35. Karnovsky, I.A.; Lebed, O. Advanced Methods of Structural Analysis; Springer: New York, NY, USA, 2010; pp. 211-270.

36. Megson, T.H.G. Structural and Stress Analysis, 3rd ed.; Elsevier Ltd.: Amsterdam, The Netherlands, 2014.

37. Kawai, Y.; Kim, J.H.; Inomata, N.; Ono, T. Parametrically actuated resonant micromirror using stiffness tunable torsional springs. Sens. Mater. 2016, 28, 131-139.

38. Zhang, H.; Xu, D.; Zhang, X.; Chen, Q.; Xie, H.; Li, S. Model-based angular scan error correction of an electrothermally-actuated MEMS mirror. Sensors 2015, 15, 30991-31004. [CrossRef] [PubMed]

39. Liu, L.; Pal, S.; Xie, H. MEMS mirrors based on a curved concentric electrothermal actuator. Sens. Actuators A 2012, 188, 349-358. [CrossRef]

40. Espinosa, A.; Rabenorosoa, K.; Clevy, C.; Komati, B.; Lutz, P.; Zhang, X.; Samuelson, S.R.; Xie, H. Piston motion performance analysis of a 3DOF electrothermal MEMS scanner for medical applications. Int. J. Optomech. 2014, 8, 179-194. [CrossRef]

41. Koh, K.H.; Qian, Y.; Lee, C. Design and characterization of a 3D MEMS VOA driven by hybrid electromagnetic and electrothermal actuation mechanics. J. Micromech. Microeng. 2012, 22, 105031. [CrossRef]

(C) 2017 by the authors. Licensee MDPI, Basel, Switzerland. This article is an open access article distributed under the terms and conditions of the Creative Commons Attribution (CC BY) license (http:/ / creativecommons.org/licenses/by/4.0/). 